\title{
Deformation Characteristics of Aluminium Composites for Structural Applications
}

\author{
Theodore E. Matikas ${ }^{1}$ and Syed T. Hasan ${ }^{2}$ \\ ${ }^{1}$ Department of Materials Science and Engineering, University of Ioannina, \\ 2 Faculty of Arts, Computing, Engineering and Sciences, Sheffield Hallam University, \\ ${ }^{1}$ Greece \\ ${ }^{2}$ United Kingdom
}

\section{Introduction}

Silicon carbide ( $\mathrm{SiC}$ ) particulate-reinforced aluminium matrix composites (AMC) are attractive engineering materials for a variety of structural applications, due to their superior strength, stiffness, low cycle fatigue and corrosion fatigue behaviour, creep and wear resistance, compared to the aluminium monolithic alloys. An important feature of the microstructure in the $\mathrm{Al} / \mathrm{SiC}$ composite system is the increased amount of thermal residual stresses, compared to unreinforced alloys, which are developed due to mismatch in thermal expansion coefficients of matrix and reinforcement phases. The introduction of the reinforcement plays a key role in both the mechanical and thermal ageing behaviour of the composite material. Micro-compositional changes which occur during the thermomechanical forming process of these materials can cause substantial changes in mechanical properties, such as ductility, fracture toughness and stress corrosion resistance.

The satisfactory performance of aluminium matrix composites depends critically on their integrity, the heart of which is the quality of the matrix/particle reinforcement interface. The nature of the interface depends in turn on the processing of the AMC component. At the micro-level, the development of local concentration gradients around the reinforcement can be very different to the nominal conditions. The latter is due to the aluminium alloy matrix attempt to deform during processing. This plays a crucial role in the micro-structural events of segregation and precipitation at the matrix-reinforcement interface.

The strength of particulate-reinforced composites also depends on the size of the particles, interparticle spacing, and the volume fraction of the reinforcement [1]. The microstructure and mechanical properties of these materials can be altered by thermo-mechanical treatment as well as by varying the reinforcement volume fraction. The strengthening of monolithic metallic material is carried out by alloying and supersaturating, to an extent, that on suitable heat treatment the excess alloying additions precipitates out (ageing). To study the deformation behaviour of precipitate hardened alloy or particulate reinforced metal matrix composites the interaction of dislocation with the reinforcing particles is much more dependent on the particle size, spacing and density than on the composition [2]. Furthermore, when a particle is introduced in a matrix, an additional barrier to the movement of dislocation is created and the dislocation must behave either by cutting through the particles or by taking a path around the obstacles [3]. 
At present, the relationship between the strength properties of metal matrix composites and the details of the thermo-mechanical forming processes is not well understood. The kinetics of precipitation in the solid state has been the subject of much attention. Early work on growth kinetics has been developed for the grain boundary case [4] and for intragranular precipitation [5]. These approaches have been integrated to produce a unified description of the inter- and intra-granular nucleation and growth mechanisms [6, 7]. More recently, successful attempts have been made to combine models of precipitate growth at interfaces with concurrently occurring segregation in aluminium alloys [8]. Studies of the relation between interfacial cohesive strength and structure have only recently become possible. This is due to of remarkable advances in physical examination techniques allowing direct viewing of interface structure and improved theoretical treatments of grain boundary structure.

The ability of the strengthening precipitates to support the matrix relies on the properties of the major alloying additions involved in the formation of these precipitates. The development of precipitates in Al-based alloys can be well characterised through heat treatment processing. Heat treatment affects the matrix properties and consequently the strain hardening of the composite. Furthermore, the distribution and concentration of these precipitates greatly affect the properties of the material where homogenous distribution of small precipitates provides the optimum results.

The role of the reinforcement is crucial in the microdeformation behaviour. The addition of $\mathrm{SiC}$ to aluminium alloy increases the strength and results in high internal stresses, in addition to the ones caused by the strengthening precipitates. Furthermore, the $\mathrm{SiC}$ reinforced particles are not affected by the heat treatment process. A great deal of attention has been recently devoted to understanding the strengthening mechanisms in metal matrix composites, which are distinguished by a large particulate volume fraction and relatively large diameter. Another important matter in understanding and modelling the strength of particulate MMCs is to consider the effect of particle shape, size and clustering [9-11], as well as the effects of clustering of reinforcement on the macroscopic behaviour and the effects of segregation to the $\mathrm{SiC} / \mathrm{Al}$ interfaces [12]. Important role also play the effects of casting condition and subsequent swaging on the microstructure, clustering, and properties of $\mathrm{Al} / \mathrm{SiC}$ composites [13].

Aluminium honeycomb sandwich panel constructions have been successfully applied as strength members of satellites and aircraft structures and also in passenger coaches of highspeed trains such as the TGV in France and the Shinkansen in Japan [14]. However, the cost of producing the all welded honeycomb structure has been a key factor for not using this technology on mass production rate. Recent developments in manufacturing methods have given rise to a range of commercially viable metallic foams, one being Alulight. In comparison to aluminium honeycomb core construction, metallic foams show isotropic properties and exhibit non linear mechanical deformation behaviour. The metallic foams have the potential to be used at elevated temperatures up to $200^{\circ} \mathrm{C}$ [15]. They also have superior impact energy absorption and improved strength and weight savings. However, the successful implementation of both aluminium honeycomb and metallic foam sandwich panels for aerospace and transportation applications is dependent upon an understanding of their mechanical properties including their resistance to fatigue crack growth and the resistance of aluminium alloys to environmentally induced cracking or stress corrosion cracking. 
This chapter discusses first the relationship between the interfacial strength with the thermo-mechanical deformation process and the resulting macroscopic mechanical behaviour of particle-reinforced aluminium matrix composites. Micro-compositional changes which occur during the thermo-mechanical processing of these materials can cause substantial changes in mechanical properties such as ductility, fracture toughness, or stress corrosion resistance. A mico-mechanistic model will be presented for predicting the interfacial fracture strength in AMCs in the presence of magnesium segregation. Finally, the use of powerful nondestructive evaluation tools, such as infrared thermography, will be discussed to evaluate the state of stresses at the crack tip and to monitor fatigue crack growth in particle-reinforced aluminium alloy matrix composites.

In the second part of the chapter the structural integrity of Aluminium Honeycomb (HC) sandwich panels is compared with the new core material concept of aluminium foams. Aluminium Honeycomb sandwich panels are used to reduce weight whilst improving the compressive strength of the structure with the aerospace industry being one of the prime users of HC sandwich panels for structural applications. The cost of producing all welded HC structures has been the key factor for not using this technology on a mass production basis. An alternative to the aluminium honeycomb $(\mathrm{HC})$ sandwich panels is the metallic foam sandwich panel, which has been gaining interest in the same field. These foams are anisotropic, exhibit non-linear mechanical behaviour, and they have the potential for use at temperatures up to $200^{\circ} \mathrm{C}$. They have superior impact energy absorption, and improved strength and weight savings. The lower weight as compared to conventional solid wrought aluminium alloys will mean a reduction in fuel consumption thus providing economical savings.

This chapter attempts to investigate whether aluminium honeycomb sandwich panels, with their homogenous hexagonal core can be successfully replaced by metallic foam sandwich panels, which have an inhomogeneous core. A successful replacement would improve the confidence of manufacturers in the exploitation of this new material in replacing traditional materials. Current levels of understanding of cyclic stressing in metallic foam sandwich panels is limited and models of long term understanding of this aspect of failure are very important for both aerospace and automotive sectors. Burman et al [16] suggests that fundamental fatigue models and concepts proven to work for metals can be applied to metallic foam sandwich panels. A study by Shipsha et al [17] investigated experimentally both metallic foam and other cellular foams, using compact tension specimens. Shipsha's et al research is extremely interesting and implies that a sandwich panel should be considered whole and not two separate entities. Banhart and Brinkers has shown that it is very difficult to detect the features leading to fatigue failure in metallic foams due to the metallic foam being already full of micro cracks [18]. However, Olurin [19] investigation suggest that the fatigue crack growth mechanism of Alulight and Alporas foam is of sequential failure of cell faces ahead of crack tip. The main conclusion is that for a given $\Delta K$, the fatigue crack propagation rate, da/dN decreases with increasing density and for a given stress intensity, the fatigue crack propagation rate increases when the mean stress is increased.

Current levels of understanding of cyclic stressing in aluminium foams is limited and models of long term understanding of this aspect of failure are important for both aerospace and automotive sectors. This is particularly important for low-density foam and honeycomb materials which despite thin ligament thickness, have good properties in compression. A method of analysis is proposed to predict life expectancy of aluminium honeycomb and metallic foam sandwich panels. 


\section{SiC-particulate reinforced aluminium matrix composites}

\subsection{Materials}

Aluminium - silicon - magnesium alloys (A359) are important materials in many industrial applications, including aerospace and automotive applications. The alloys from the Al-Si$\mathrm{Mg}$ system are the most widely used in the foundry industry thanks to their good castability and high strength to weight ratio. Materials based on A359 matrix reinforced with varying amounts of silicon carbide particles are discussed in this chapter.

Four types of material are used: 1 ) Ingot as received $\mathrm{A} 359 / 40 \% \mathrm{SiC}$, with an average particle size of $19 \pm 1$ micron, 2) Ingot as received $\mathrm{A} 359 / 25 \% \mathrm{SiC}$, with an average particle size of $17 \pm 1$ micron, 3) Hot rolled as received $\mathrm{A} 359 / 31 \% \mathrm{SiC}$ with an average particle size of $17 \pm 1$ micron and 4) Cast alloy as received $\mathrm{A} 359 / 30 \% \mathrm{SiC}$ with particles of $\mathrm{F} 400$ grit, with an average particle sizes of $17 \pm 1$ micron. Table 1, contains the details of the chemical composition of the matrix alloy as well as the amount of silicon carbide particles in the metal matrix composites.

\begin{tabular}{|l|c|c|c|c|c|c|c|}
\hline TYPES & Si & $\mathbf{M g}$ & $\mathbf{M n}$ & $\mathbf{C u}$ & $\mathbf{F e}$ & $\mathbf{Z n}$ & $\mathbf{S i C}$ \\
\hline $\begin{array}{l}\text { INGOT } \\
\text { A359 }\end{array}$ & 9.5 & 0.5 & 0.1 & 0.2 & 0.2 & 0.1 & 40 \\
\hline $\begin{array}{l}\text { INGOT } \\
\text { A359 }\end{array}$ & 9.5 & 0.5 & 0.1 & 0.2 & 0.2 & 0.1 & 25 \\
\hline $\begin{array}{l}\text { CAST } \\
\text { A359 }\end{array}$ & 9.5 & 0.5 & 0.1 & 0.2 & 0.2 & 0.1 & 30 \\
\hline $\begin{array}{l}\text { ROLLE } \\
\text { D A359 }\end{array}$ & 9.5 & 0.5 & 0.1 & 0.2 & 0.2 & 0.1 & 31 \\
\hline
\end{tabular}

Table 1. Types and composition of the material

The microstructure of such materials consists of a major phase, aluminium or silicon and the eutectic mixture of these two elements. In this system, each element plays a role in the material's overall behaviour. In particular, $\mathrm{Si}$ improves the fluidity of $\mathrm{Al}$ and also Si particles are hard and improve the wear resistance of Al. By adding $\mathrm{Mg}$, Al - Si alloy become age hardenable through the precipitation of $\mathrm{Mg}_{2} \mathrm{Si}$ particulates.

\subsection{Heat treatment}

Properties in particulate-reinforced aluminium matrix composites are primarily dictated by the uniformity of the second-phase dispersion in the matrix. The distribution is controlled by solidification and can be later modified during secondary processing. In particular, due to the addition of magnesium in the A359 alloy, the mechanical properties of this material can be greatly improved by heat treatment process. There are many different heat treatment sequences and each one can modify the microstructural behaviour as desired [20]. Precipitation heat treatments generally are low temperature, long-term processes. Temperatures range from $110^{\circ} \mathrm{C}$ to $195^{\circ} \mathrm{C}$ for 5 to 48 hours. The selection of the time temperature cycles for precipitation heat treatment should receive careful consideration. Larger precipitate particulates result from longer times and higher temperatures. On the other hand, the desired number of larger particles formed in the material in relation to their interparticle spacing is a crucial factor for optimising the strengthening behaviour of the composite. The objective is to select the heat treatment cycle that produces the most 
favourable precipitate size and distribution pattern. However, the cycle used for optimising one property, e.g. tensile strength, is usually different from the one required to optimise a different property, e.g. yield strength, corrosion resistance.

Heat treatment of composites though has an additional aspect to consider, the particles introduced in the matrix. These particles may alter the alloy's surface characteristics and increase the surface energies [21].

The heat treatments were performed in Carbolite RHF 1200 furnaces with thermocouples attached, ensuring constant temperature inside the furnace. There were two different heat treatments used in the experiments, T6 and modified-T6 (HT-1) [21, 22].

The T6 heat treatment consists of the following steps: solution heat treatment, quench and age hardening (Fig. 1).

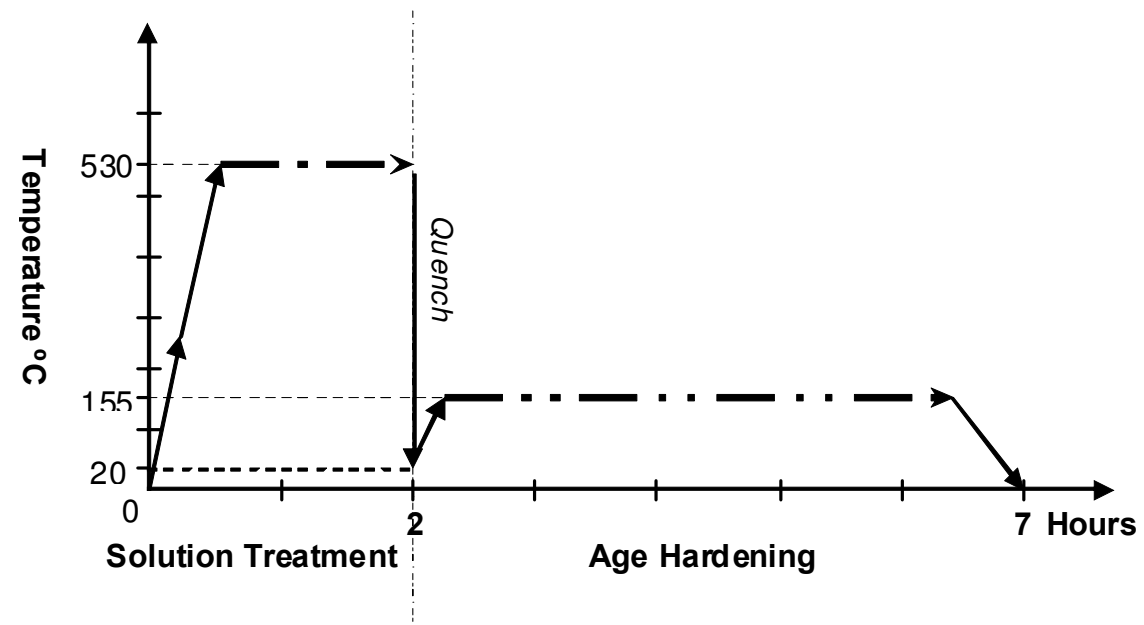

Fig. 1. T6 Heat treatment diagram showing the stages of the solution treatment for 2 hours and artificial ageing for $5 \mathrm{~h}$

In the solution heat treatment, the alloys have been heated to a temperature just below the initial melting point of the alloy for 2 hours at $530 \pm 5^{\circ} \mathrm{C}$ where all the solute atoms are allowed to dissolve to form a single phase solid solution. Magnesium is highly reactive with Silicon at this temperature and precipitation of $\mathrm{Mg}_{2} \mathrm{Si}$ is expected to be formed. The alloys were then quenched to room temperature. In age hardening, the alloys were heated to an intermediate temperature of $155^{\circ} \mathrm{C}$ for 5 hours where nucleation and growth of the $\beta^{\prime}$ phase. The desired $\beta$ phase $\mathrm{Mg}_{2} \mathrm{Si}$ precipitated at that temperature and then cooled at room temperature conditions. The precipitate phase nucleates within the grains at grain boundaries and in areas close to the matrix-reinforcement interface, as uniformly dispersed particles. The holding time plays a key role in promoting precipitation and growth which results in higher mechanical deformation response of the composite.

The second heat treatment process was the modified-T6 (HT-1) heat treatment, where in the solution treatment the alloys have been heated to a temperature lower than the T6 heat treatment, at $450 \pm 5^{\circ} \mathrm{C}$ for 1 hour, and then quenched in water. Subsequently the alloys were heated to an intermediate temperature of $170 \pm 5^{\circ} \mathrm{C}$ for 24 hours in the age hardened stage and then cooled in air (Fig. 2). 


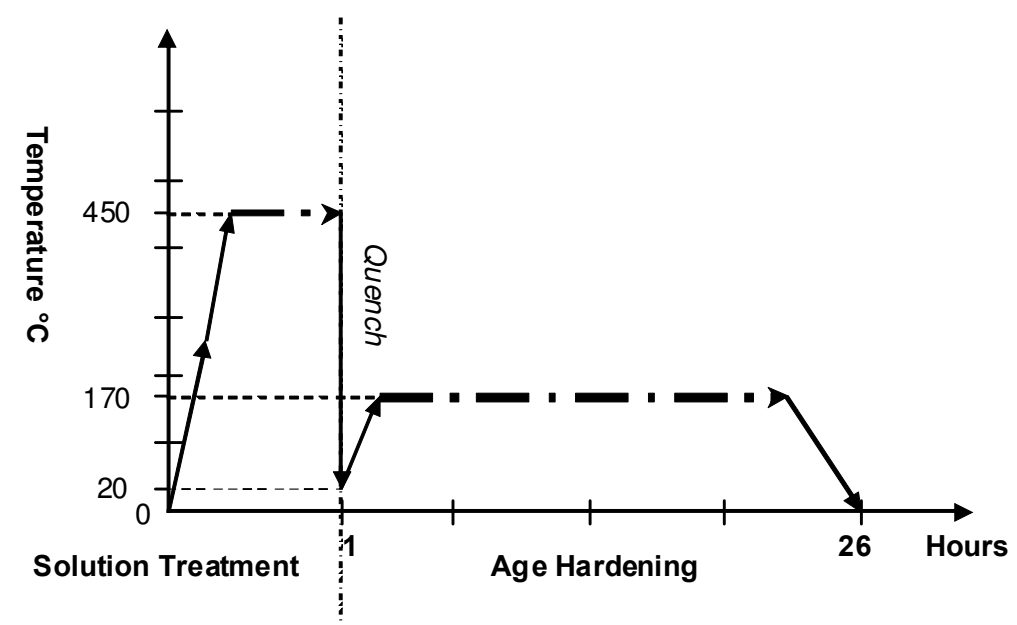

Fig. 2. Modified T6 (HT-1) showing stages of solution treatment for 1 hour and artificial ageing for $24 \mathrm{~h}$

In both heat treatments undesired formation of phases, like the $\mathrm{Al}_{4} \mathrm{C}_{3}$, is a possibility and selection of the solution treatment as well as the age hardening processes should be carefully considered. Temperature and time control, therefore, is extremely important during heat treatment. If the melt temperature of $\mathrm{SiC} / \mathrm{Al}$ composite materials rises above a critical value, $\mathrm{Al}_{4} \mathrm{C}_{3}$ is formed increasing the viscosity of the molten material, which can result in severe loss of corrosion resistance and degradation of mechanical properties in the cast composite; excessive formation of $\mathrm{Al}_{4} \mathrm{C}_{3}$ makes the melt unsuitable for casting. In the $\mathrm{A} 359 / \mathrm{SiC}$ composite high silicon percentage added in excess aids to the formation of some oxides $\left(\mathrm{SiO}_{2}\right)$ around the $\mathrm{SiC}$ reinforcement, something that retards the formation of $\mathrm{Al}_{4} \mathrm{C}_{3}$, since such oxides prevent the dissolution of $\mathrm{SiC}$ particles [22].

\subsection{Metallographic examination}

In order to analyse the microstructure, a series of sample preparation exercises were carried out, consisted of the cutting, mounting, grinding and polishing of the samples. The microstructures were investigated by SEM, EDAX, and XRD to determine the $\mathrm{Al} / \mathrm{SiC}$ area percentage, size and count of particulates.

The microstructures of the examined MMCs in the as received condition have four distinct micro phases as clearly marked on the image micrograph, which are as follows: the aluminium matrix, the SiC particles, the eutectic region of aluminium and silicon and the $\mathrm{Mg}$ phase (Fig. 3). The distribution of $\mathrm{SiC}$ particles was found to be more or less uniform, however, instances of particle free zones and particle clustered zones were observed.

Matrix-reinforcement interfaces were identified by using high magnification Nano-SEM. In the as received hot rolled images the $\mathrm{Al}$ Matrix/SiC reinforcement interface is clearly identified (Fig. 4). These interfaces attain properties coming from both individual phases of constituents and facilitate the strengthening behaviour of the composite material.

In the modified T6 (HT-1) condition the microsturucture of the cast $30 \% \mathrm{SiC}$ has the same phases as in the as received state, plus one rod-shape phase (Fig.5) along the matrix and at the matrix-reinforcement interface has been identified to be $\mathrm{Mg}_{2} \mathrm{Si}$ precipitates in an early 
stage which are not fully grown. This evidence shows that $\beta^{\prime}$ phase has been formed with magnesium and silicon reacting together but $\beta$ phases forming platelets of precipitates have not been formed in this HT-1 heat treatment, and this is probably due to the solution treatment temperature that did not allow enough reactivity time between the main alloying elements.

In the rolled $20 \% \mathrm{SiC}$ the microstructure of HT-1 heat treatment shows an increase of the Silicon phase as shown in the image (Fig. 6). Silicon has been expanded during solidification and subsequent ageing. This formed round areas around the whole area of the composite. Comparing with the cast $30 \% \mathrm{SiC}$ sample, in the rolled material the silicon phase is

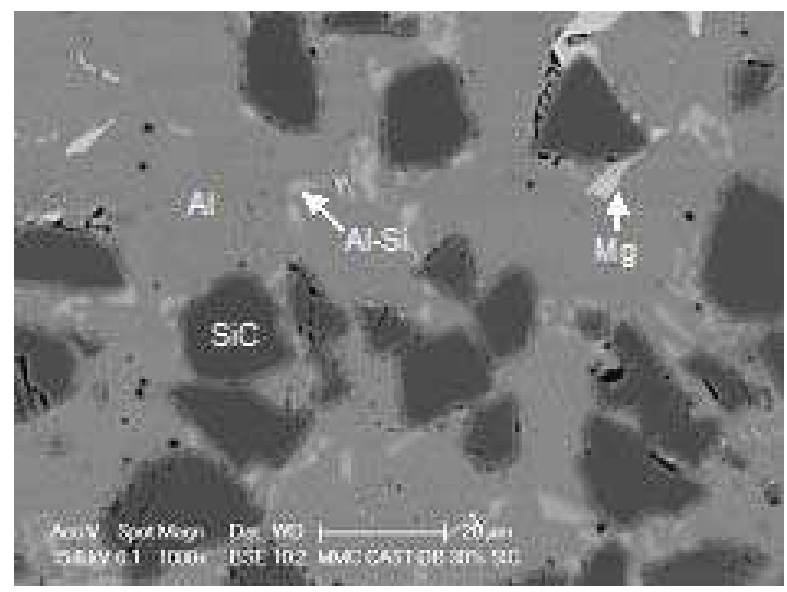

Fig. 3. Microstructure of cast $30 \% \mathrm{SiC}$ in the as received condition showing four distinct phases: Aluminium matrix, $\mathrm{SiC}$ particles, eutectic region of aluminium and silicon and $\mathrm{Mg}$ phase

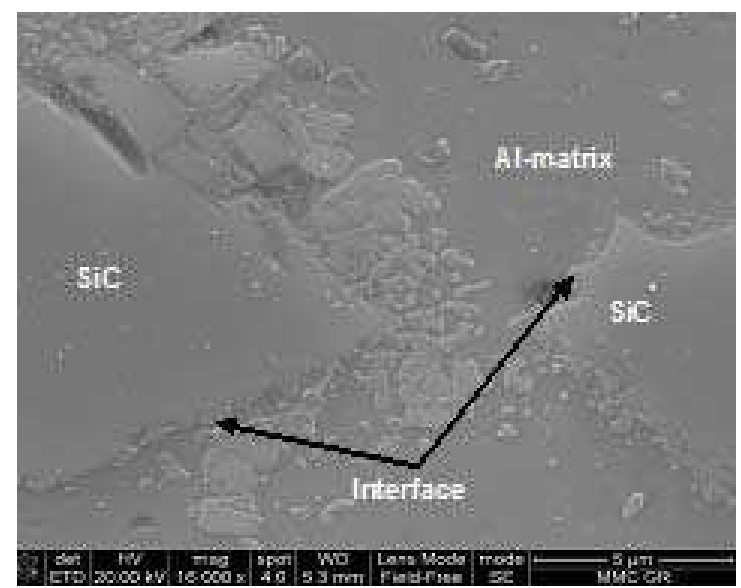

Fig. 4. Microstructure of rolled $31 \% \mathrm{SiC}$ in the as received condition showing matrixreinforcement interfaces 
increased by $6 \%$. This increase under the same heat treatment conditions is explained by the difference in the percentage of reinforcement in the material. Therefore, it becomes evident that the introduction of $\mathrm{SiC}$ reinforcement promotes zone kinetics and phase formation reactions during heat treatment process. The reinforcement, depending on its percentage in the matrix material, accelerates or restrains events such as precipitation and segregation. This is further supported by the fact that precipitation has not been observed in the HT-1 heat treated $20 \% \mathrm{SiC}$ rolled material, where lower percentage of $\mathrm{SiC}$ reinforcement sloweddown the precipitation kinetics and $\beta^{\prime}$ phases could not be created in a similar manner as the $30 \%$ SiC cast sample.

In the T6 condition the microstructural results showed that in the rolled $31 \% \mathrm{SiC}$ sample precipitates of $\mathrm{Mg}_{2} \mathrm{Si}$ have been formed in the matrix in a platelet shape with a size of around 1-3 $\mu \mathrm{m}$, as well as in areas close to the interface (Fig. 7). The higher solution temperature and lower age hardening holding time that exist in the T6 heat treatment process, promoted the forming of this type of precipitates which more densely populated

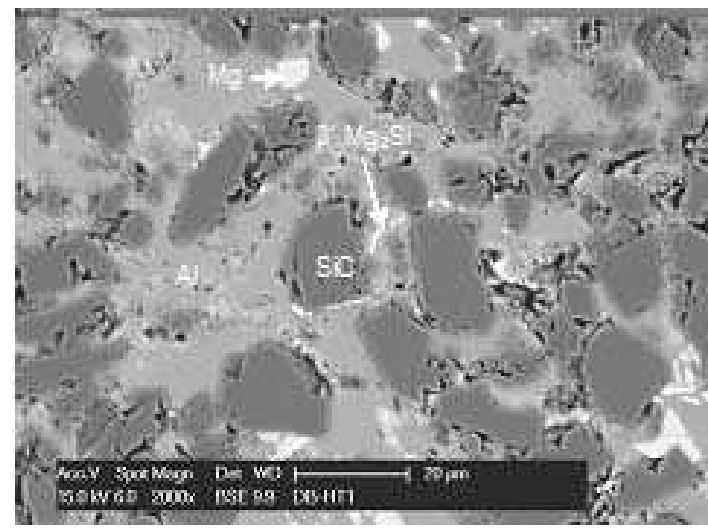

Fig. 5. Microstructure of cast $30 \% \mathrm{SiC}$ in the HT- 1 condition showing rod shape $\beta^{\prime}$ phases of $\mathrm{Mg}_{2} \mathrm{Si}$ around the matrix and the interface of the reinforcement

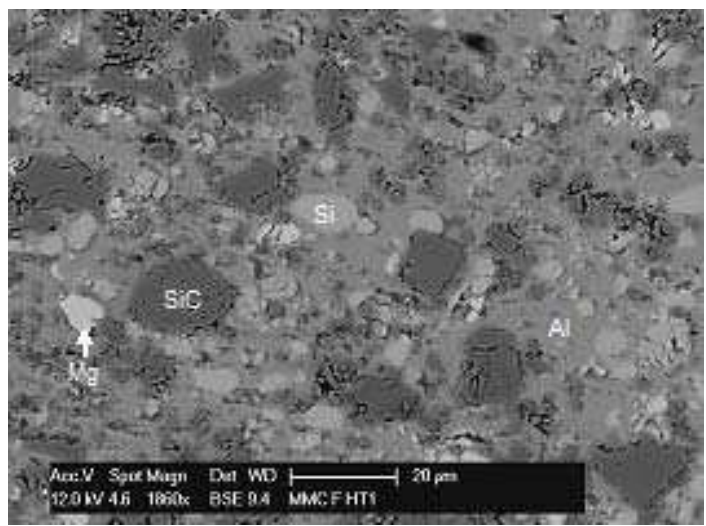

Fig. 6. Hot rolled HT-1 sample showing phases of Aluminium, SiC, Silicon, Mg 
the interface region compared to the matrix. In the case of presence of a crack in the matrix, the precipitates act as strengthening aids promoting crack deflection at the interface resulting in an increase of the composite's fracture toughness [20, 23]. Furthermore, the precipitates formed in the matrix act as support to strengthening mechanisms of the reinforcement-matrix interface.

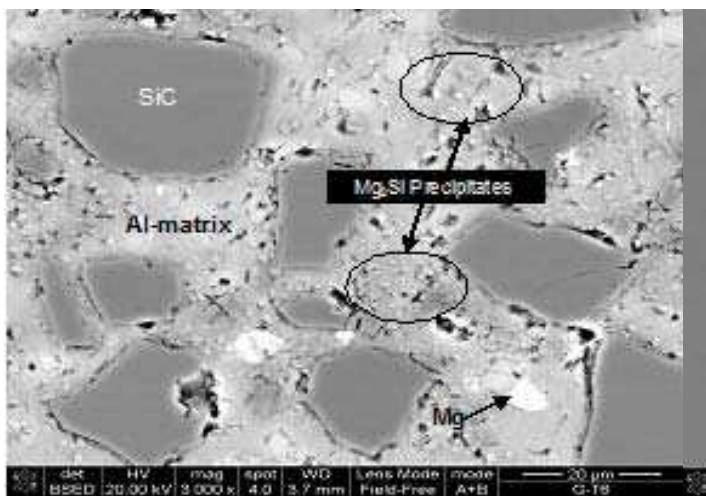

(a)

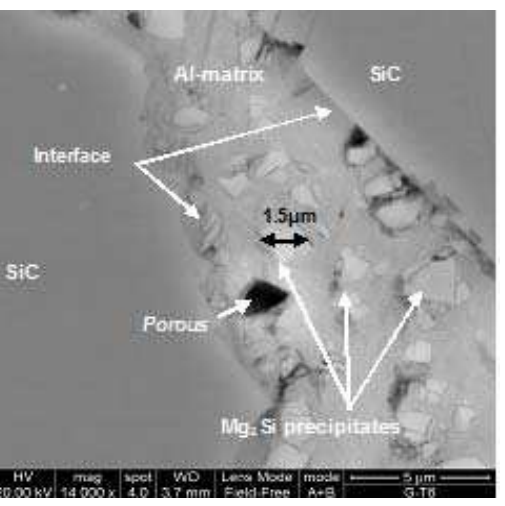

(b)

Fig. 7. (a) Hot rolled $31 \% \mathrm{SiC}-\mathrm{T} 6$ showing precipitate formed around the reinforcement. (b) Hot rolled $31 \% \mathrm{SiC}-\mathrm{T} 6$ showing $\mathrm{Mg}_{2} \mathrm{Si}$ precipitates formed between the SiC reinforcement interface in a platelet shape of around 1-3 $\mu \mathrm{m}$. A porous close to the interface has been identified in a similar size

The X-ray diffraction was carried out on the MMCs in the as received, as well as, in the heat treatment conditions, in samples with $20 \%, 30 \%$ and $31 \%$ of $\mathrm{SiC}$ particulates. Even though some peaks were superimposed, the results clearly showed the phases present in the microstructures. In particular, in the as received condition and in the heat treatment conditions the results showed existence of aluminium matrix material, eutectic silicon, $\mathrm{SiC}$, $\mathrm{Mg}_{2} \mathrm{Si}, \mathrm{SiO}_{2}$ phases as the distinct ones, and also $\mathrm{MgAl}_{2} \mathrm{O}_{4}$ and $\mathrm{Al}_{2} \mathrm{O}_{3}$ phases. $\mathrm{MgAl}_{2} \mathrm{O}_{4}$ and $\mathrm{Al}_{2} \mathrm{O}_{3}$ oxides give good cohesion between matrix and reinforcement when forming a continuous film at the interface. The presence of $\mathrm{MgAl}_{2} \mathrm{O}_{4}$ (spinel) shows that low percentage of magnesium reacted with $\mathrm{SiO}_{2}$ at the surface of $\mathrm{SiC}$ and formed this layer in the interphacial region between the matrix and the reinforcement.

$$
2 \mathrm{SiO}_{2}+2 \mathrm{Al}+\mathrm{Mg} \rightarrow \mathrm{MgAl}_{2} \mathrm{O}_{4}+2 \mathrm{Si}
$$

The layers of $\mathrm{MgAl}_{2} \mathrm{O}_{4}$ protect the $\mathrm{SiC}$ particles from the liquid aluminium during production or remelting of the composites. This layer provides more than twice bonding strength compared to $\mathrm{Al}_{4} \mathrm{C}_{3}$. Furthermore, the layer of $\mathrm{Al}_{2} \mathrm{O}_{3}$ oxide is formed as a coating when $\mathrm{SiO}_{2}$ is reacting with liquid aluminium.

$$
3 \mathrm{SiO}_{2}+4 \mathrm{Al} \rightarrow 2 \mathrm{Al}_{2} \mathrm{O}_{3}+3 \mathrm{Si}
$$

The same phases have been identified in the HT- 1 modified condition. In the T6 condition XRD results showed one more phase present which is the spinel-type mixed oxide $\mathrm{MgFeAlO}_{4}$ showing that Fe trace reacted with $\mathrm{Mg}$ and in the presence of aluminium and oxygen formed this oxide. 


\subsection{Micro-hardness testing}

The three samples have been compared in relation to their microhardness performance based on the reinforcement percentage, the heat treatment conditions and the different manufacturing forming processes. Microhardness of the three composites has been measured in order to get the resistance of the material to indentation, under localized loading conditions. The microhardness test method, according to ASTM E-384, specifies a range of loads using a diamond indenter to make an indentation, which is measured and converted to a hardness value [21, 22].

Measuring the different phases in the micro-level it is quite challenging, as the $\mathrm{SiC}$ reinforcement of $\approx 17 \mu \mathrm{m}$ in size was not easy to measure, due to small indentation mark left when a small load on the carbide is applied. When introducing higher values of load, the indentation was not localized in the carbide but covered some of the matrix area too. The load was finally set to 50 grams in order to obtain valid measurements coming from different areas of the samples: $\mathrm{SiC}$, aluminium matrix, and the overall composite i.e. areas superimposing matrix and reinforcement.

There are many factors influencing the microhardness of a composite material, including the reinforcement percentage, interparticle spacing and also particle size. Moreover, manufacturing forming processes influence material's microhardness behaviour in relation to the reinforcement percentages in the composites.

The cast sample in the as received condition has the highest MMC microhardness, where the rolled $20 \% \mathrm{SiC}$ with lower percentage of reinforcement has the lowest values. By altering the microstructure with modified T6 (HT-1) heat treatment all values of the three samples show an increase between $20-45 \%$ from the initial state (Fig. 8). This shows the effect of the heat treatment in the micro-deformation of the matrix-reinforcement interface due to the presence of precipitates and other phases and oxide layers.

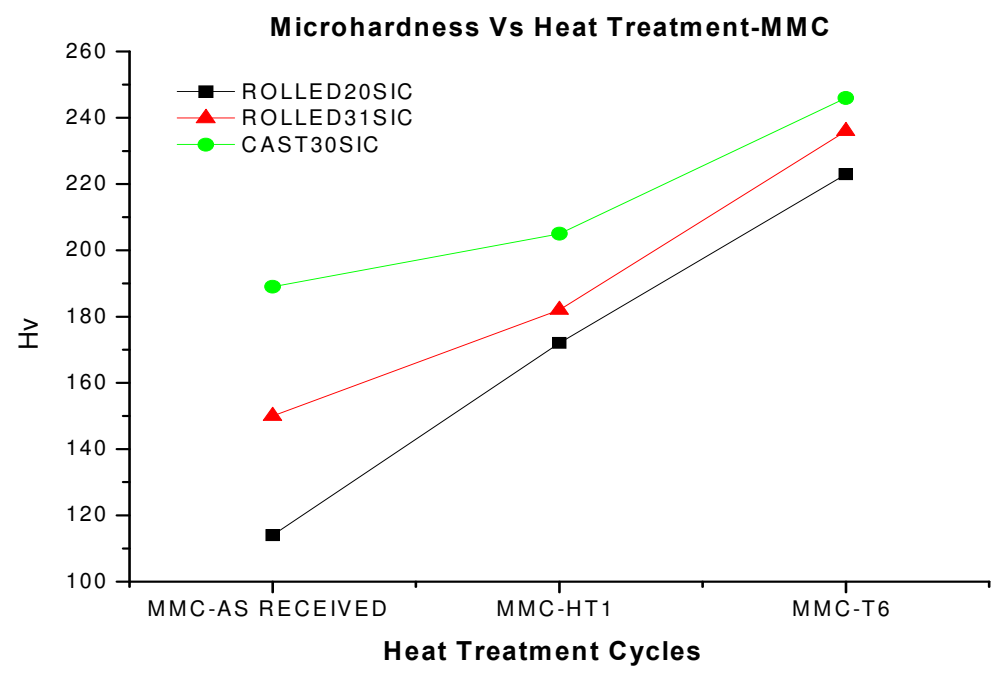

Fig. 8. Microhardness values Vs. Heat treatment cycles for the MMC areas

In the $\mathrm{T} 6$ condition it was observed the larger increase in microhardness values from the as received state, ranging from $20 \%$ to $90 \%$ depending on the reinforcement percentage and 
manufacturing process. In particular, in the rolled $20 \% \mathrm{SiC}$ material the increase in microhardness values is in the order of $90 \%$.

Furthermore, variability in microhardness values was observed when comparing cast and rolled materials with different percentage of SiC. However, this variability varied when samples processed at different heat treatment conditions were compared. Highest variability showed samples in the as received condition, whereas lowest variability showed samples in the T6 condition, with samples in the HT-1 condition in between. This can be explained by the fact that precipitates act as strengthening mechanisms and affect the micromechanical behaviour of the composite material.

In the absence of precipitates (in the as received condition), the volume percentage of $\mathrm{SiC}$ and the manufacturing processing play a significant role in micromechanical behaviour of the composite. As precipitates are formed due to heat treatment process they assume the main role in the micromechanical behaviour of the material. In the HT-1 heat treatment condition there is presence of $\beta^{\prime}$ precipitates which affect the micromechanical behaviour in a lesser degree than in the case of T6 heat treatment condition where fully grown $\beta$ precipitates are formed. It becomes clear that after a critical stage, which if related to the formation of $\beta$ precipitates in the composite the dominant strengthening mechanism is precipitation hardening.

While Figure 8 shows results in areas that include the interface region (where precipitates are concentrated) Figure 9, shows results on microhardness values in the aluminium matrix (where precipitates are dispersed). In Figure 9 there is similar variability for all three materials processing states, as received, HT-1, and T6. This implies that in the matrix material the percentage of the reinforcements, the manufacturing process, as well as the precipitation hardening, are strengthening mechanisms of equal importance.

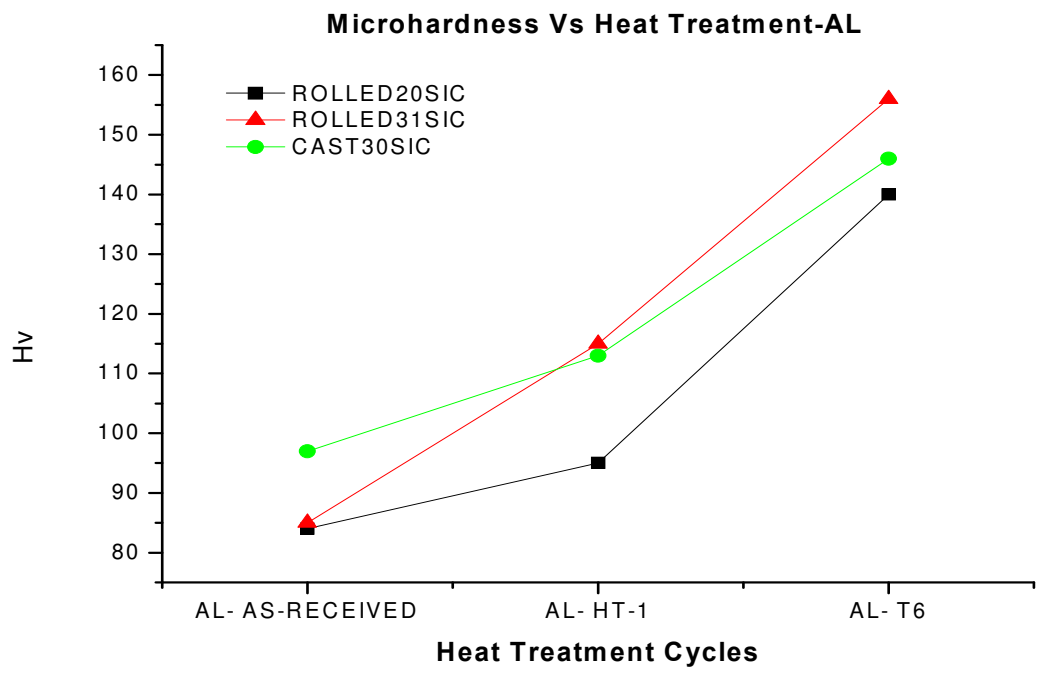

Fig. 9. Microhardness Vs. Heat treatment cycles for Aluminium areas

Figure 10 shows microhardness measurements obtained from areas around the matrixreinforcement interface in a composite heat treated in the T6 condition. The microhardness 
values are higher in the close proximity of the interface. It is observed that cast material has higher values than the rolled material. In the case of rolled material, the microhardness raises as the percentage of reinforcement increases.

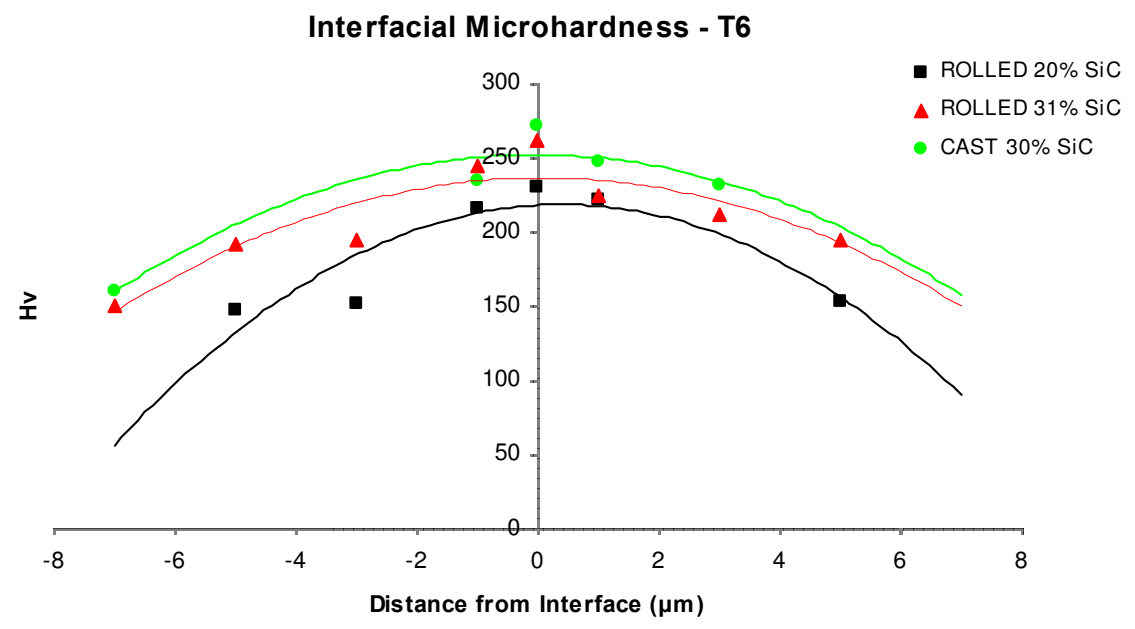

Fig. 10. Interfacial microhardness showing measurements obtained from areas close to the matrix- reinforcement interface in the T6 condition

\subsection{Tensile testing}

Aluminium - SiC particulate composite samples were tested in tension for two different volume fractions, $20 \%$ and $31 \%$, in reinforcement [23]. The dog-bone coupons were tested according to ASTM E8-04 in the as received and, following two different heat treatments, modified T6 (HT-1) and T6 heat treatment conditions.. The mechanical properties of the composites are presented in Table 2.

\begin{tabular}{|c|c|c|c|c|c|c|}
\hline Material & Condition & $\sigma_{0,2}(\mathrm{MPa})$ & $\sigma_{w s}(\mathbf{M P a})$ & $\varepsilon(\%)$ & E & $\mathrm{HV}_{0.5}$ \\
\hline $\begin{array}{l}\text { Rolled A1 A.359- } \\
\text { SiC-20p }\end{array}$ & $\begin{array}{c}\text { T1 } \\
\text { HT-1 } \\
\text { T6 }\end{array}$ & $\begin{array}{l}146 \\
147 \\
326\end{array}$ & $\begin{array}{l}157 \\
190 \\
360\end{array}$ & $\begin{array}{c}1.5 \\
4 \\
2.1\end{array}$ & $\begin{array}{l}100 \\
102 \\
112\end{array}$ & $\begin{array}{l}114 \\
172 \\
223\end{array}$ \\
\hline $\begin{array}{l}\text { Rolled A1 A359- } \\
\text { SiC-31p }\end{array}$ & $\begin{array}{c}\mathrm{T1} \\
\mathrm{HT}-1 \\
\mathrm{~T} 6\end{array}$ & $\begin{array}{l}158 \\
155 \\
321\end{array}$ & $\begin{array}{l}168 \\
187 \\
336\end{array}$ & $\begin{array}{c}1 \\
2 \\
1.3\end{array}$ & $\begin{array}{l}108 \\
110 \\
116\end{array}$ & $\begin{array}{l}150 \\
182 \\
236\end{array}$ \\
\hline
\end{tabular}

Table 2. The mechanical properties of $\mathrm{Al} / \mathrm{SiC}$ Composites

The engineering stress/strain curves of the composite are shown in Figure 11. As can be clearly seen in Figure 11, the HT-1 heat treatment improved both the strength and strain to failure than the untreated composites for both volume fractions. Furthermore, the failure 
strain for this temper is considerably higher than for the T6 heat treatment; this may be attributed either to the nucleation of the $\beta$ precipitate phases which although not yet visible, may lead to the increase of the plastic deformation through crack deflection mechanisms and/or to annealing which acts competitively to the precipitation leading to the toughening of the composite. However, the T6 heat treatment exhibits the highest strength followed by the HT-1 and the as received state. Finally, as was expected, the "as received" composites behaviour in tension deteriorates with increasing filler concentration. The experiments showed that for the same range of conditions tested, the yield and the ultimate tensile strengths of the $\mathrm{SiC} / \mathrm{Al}$ composites were mainly controlled by the percentage of reinforcement as well as by the intrinsic yield/tensile strengths of the matrix alloys. The addition of the $\mathrm{SiC}$ reinforcement created stress concentrations in the composite, and thus the aluminium alloy could not achieve its potential strength and ductility due to the induced embrittlement. Composites in the as-received condition failed in a brittle manner with increasing percentage of reinforcement. As a result, with increasing reinforcement content, the failure strain of the composites was reduced as shown in Figure 11. From the above postulations it is obvious that the phase that dominates the mechanical behaviour of the composite is the precipitation phase created by age hardening while the reinforcement phase plays a secondary role.

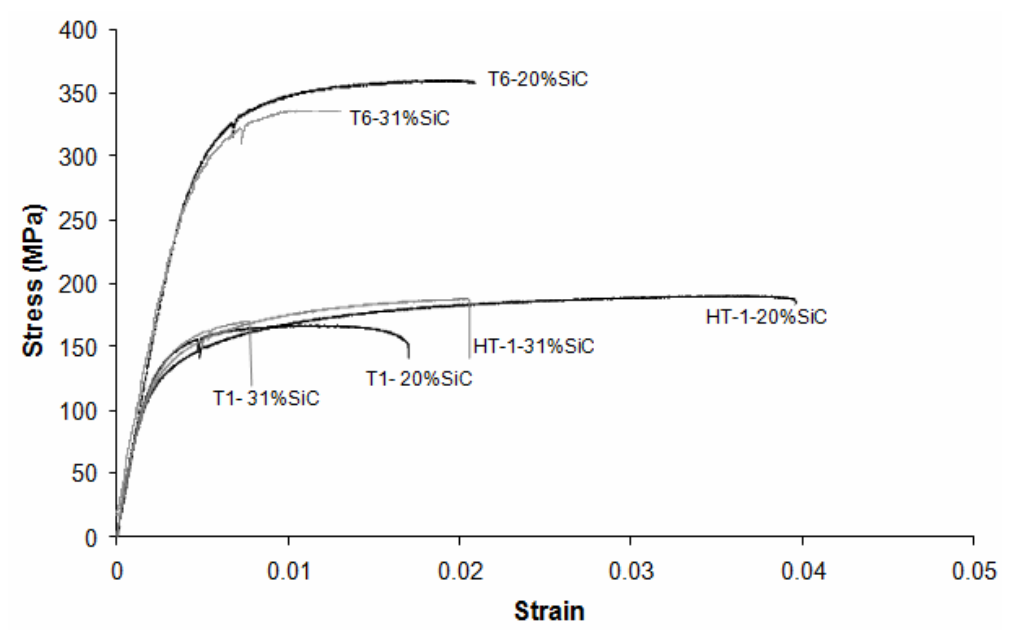

Fig. 11. Stress / Strain curves of $\mathrm{Al} / \mathrm{SiC}$ Composites

The heat treatment affected the modulus of elasticity of the composites by altering the transition into plastic flow (see Table 2 and Fig. 12). Composites in the T6 condition strained elastically and then passed into a normal decreasing-slope plastic flow. Composites tested in the HT-1 condition exhibit a greater amount of strain than the as received and those heat treated in the T6 condition. The failure strain increasing from about $1.5 \%$ strain to about $4 \%$ but the greater influence was a sharper slope of the stress-strain curve at the inception of plastic flow.

This increase in elastic proportional strain limit and the steepening of the stress-strain curve were reflected by the higher yield and ultimate tensile strengths observed in the heat-treated composites. The increase in flow stress of composites with each heat-treatable matrix 
probably indicated the additive effects of dislocation interaction with both the alloy precipitates and the $\mathrm{SiC}$ reinforcement. The combination increased the strain in the matrix by increasing the number of dislocations and requiring higher flow stresses for deformation, resulting in the higher strengths observed. Ductility of $\mathrm{SiC} / \mathrm{Al}$ composites, as measured by strain to failure, is again a complex interaction of parameters. However, the prime factors affecting these properties are the reinforcement content, heat treatment and precipitation hardening.

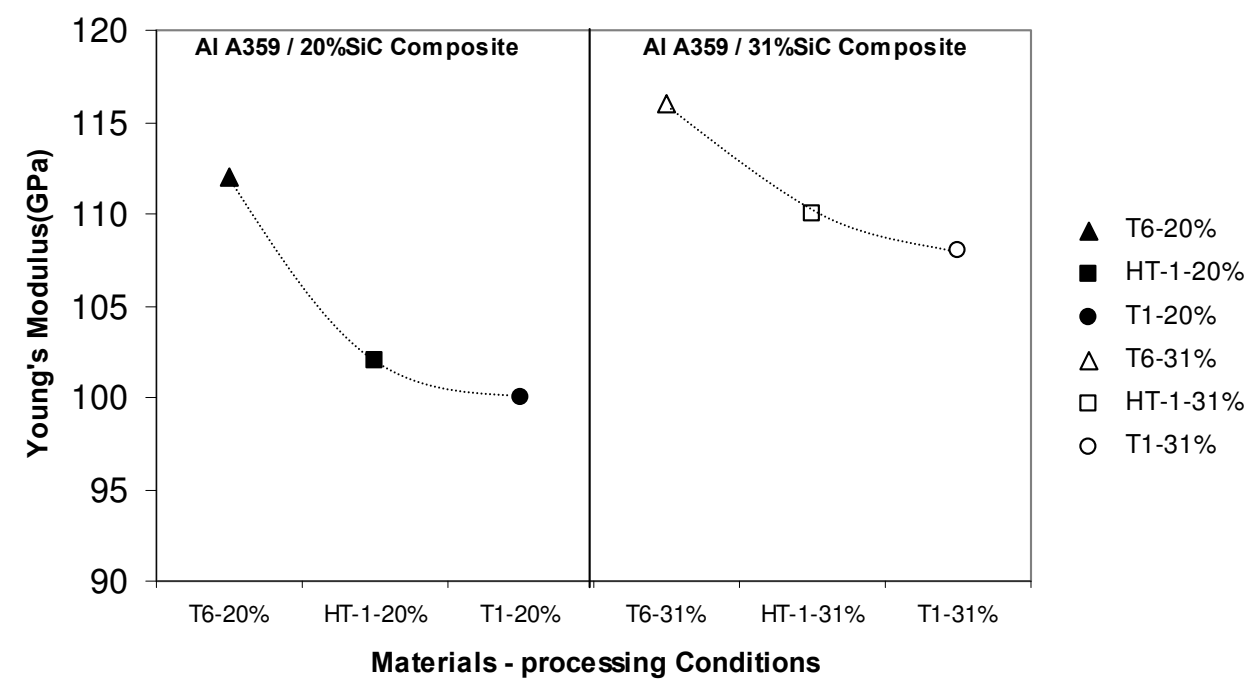

Fig. 12. Young's Modulus vs. Processing Conditions curves showing T6 treated composites having the highest modulus

\subsection{Fracture toughness KIC testing}

The plane strain fracture toughness test involves the loading to failure of fatigue precracked, notched specimens in tension or in three-point bending. The calculation of a valid toughness value can only be determined after the test is completed, via examination of the load-displacement curve and measurement of the fatigue-crack length. The provisional fracture toughness value, $\mathrm{K}_{\mathrm{Q}}$, is first calculated from the following equation:

$$
K_{Q}=\left(\frac{P_{Q}}{B W^{1 / 2}}\right) \cdot f\left(\frac{a}{W}\right)
$$

where $\mathrm{P}_{\mathrm{Q}}$ is the load corresponding to a defined increment of crack length, $\mathrm{B}$ is the specimen's thickness, $W$ is the width of the specimen, and $f(\alpha / W)$ is a geometry dependent factor that relates the compliance of the specimen to the ratio of the crack length and width, expressed as follows:

$$
f\left(\frac{a}{W}\right)=\frac{(2+a / W)\left(0.86+4.64 a / W-13.32 a^{2} / W^{2}+14.72 a^{3} / W^{3}-5.6 a^{4} / W^{4}\right)}{(1-a / W)^{3 / 2}}
$$


Only when specific validity criteria are satisfied, the provisional fracture toughness, $\mathrm{K}_{\mathrm{Q}}$, can be quoted as the valid plane strain fracture toughness, $\mathrm{K}_{\mathrm{IC}}$. The standard used for conducting this experiment, ASTM E399, imposes strict validity criteria to ensure that the plane strain conditions are satisfied during the test. These criteria include checks on the form and shape of the load versus displacement curve, requirements on specimen's size and crack geometry, and the $0.2 \%$ proof strength values at the test temperature. Essentially, these conditions are designed to ensure that the plastic zone size associated with the precrack is small enough so that plane strain conditions prevail, and that the linear elastic fracture mechanics approach is applicable.

Fracture toughness tests were conducted using a servo-hydraulic universal testing machine with data acquisition controller. The system was operated on load control for the fatigue pre-cracking stage, and on position control for the crack opening displacement (COD) testing. The fatigue test for pre-cracking was conducted at a frequency of $1 \mathrm{~Hz}$, at a load ratio $\mathrm{R}=0.25$ and load range of $3.7-4.5 \mathrm{KN}$ according to the materials' ultimate tensile strength. The COD was monitored by a clip gauge attached to the specimen with a testing rate set at $1 \mathrm{~mm} / \mathrm{min}$. Moreover, a thermal camera was set for thermographic monitoring of the crack opening displacement. Compact tension (CT) specimens were prepared for fracture toughness tests according to ASTM E399. The thickness B of the specimens was 9.2 $\mathrm{mm}$ for the MMC, and $5 \mathrm{~mm}$ for the unreinforced aluminium alloys.

Provisional $\mathrm{K}_{\mathrm{Q}}$ values were calculated according to ASTM E399 standard for all specimens according to Equations (1) and (2), where $\mathrm{Pq}=$ Pmax. Load versus displacement curves for $\mathrm{Al} / \mathrm{SiCp}$ composites and unreinforced aluminium alloys are shown in Fig. 13. Fracture toughness data for $\mathrm{Al} / \mathrm{SiCp}$ and unreinforced aluminium alloys are summarised in Table 2.

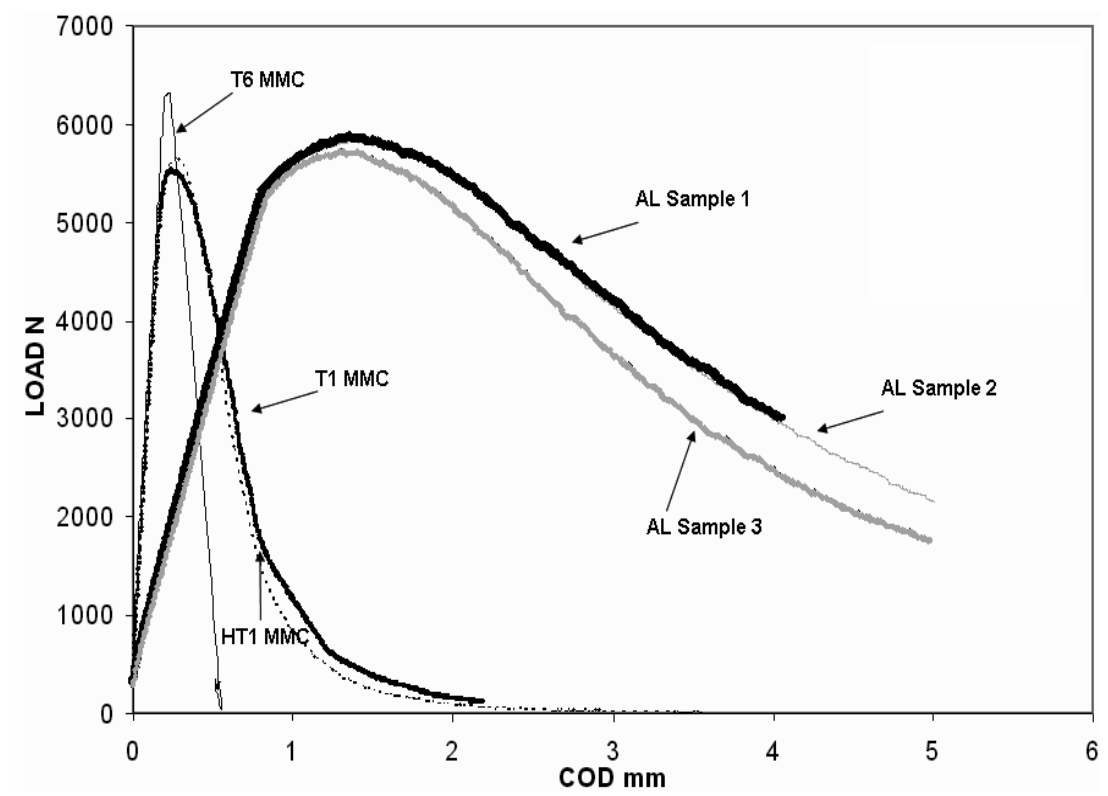

Fig. 13. Load - Displacement curves for Al/SiCp composites subjected to T1, T6 and HT-1 heat treatment conditions and three unreinforced aluminium alloy samples 


\begin{tabular}{|c|c|c|c|c|c|c|c|c|c|}
\hline Material & $\begin{array}{c}\text { Heat } \\
\text { Treatm } \\
\text { ent }\end{array}$ & $\begin{array}{c}\mathrm{E} \\
(\mathrm{GPa})\end{array}$ & $\begin{array}{l}\mathbf{R p}_{0.2} \\
(\mathrm{MPa})\end{array}$ & $\begin{array}{c}\text { B } \\
(\mathrm{mm})\end{array}$ & $a / W W$ & $\begin{array}{c}\alpha_{\text {eff }} \\
(\mathrm{mm})\end{array}$ & $\begin{array}{c}\mathrm{K}_{0} \\
(\mathrm{MPa} \\
\left.\mathbf{V}_{\mathbf{m}}\right)\end{array}$ & Valid & Reason \\
\hline 2000 series $\mathrm{Al}$ & $\mathrm{AR}$ & 71 & 75 & 5.10 & 0.552 & 27.62 & 55,36 & No & $2^{* *}$ \\
\hline 2000 series $\mathrm{Al}$ & AR & 71 & 78 & 5.13 & 0.555 & 26.76 & 56,00 & No & $2^{* *}$ \\
\hline 2000 series $\mathrm{Al}$ & AR & 71 & 72 & 5.00 & 0.558 & 28.43 & 58,48 & No & $2^{* *}$ \\
\hline A359/SIC/31p & T1 & 106 & 117 & 9.20 & 0.456 & 20.79 & 19,28 & Yes & - \\
\hline A359/SIC/31p & T6 & 108 & 120 & 9.21 & 0.462 & 20.12 & 22,05 & Yes & - \\
\hline A359/SIC/31p & HT1 & 116 & 157 & 9.20 & 0.467 & 21.33 & 20.75 & Yes & - \\
\hline $\begin{array}{c}\text { A357/SIC/20p } \\
{[16]}\end{array}$ & - & - & 215 & - & - & - & 18.60 & - & - \\
\hline $\begin{array}{c}\mathbf{A 3 5 9 / S I C / 1 0 p} \\
{[16]}\end{array}$ & - & - & 300 & - & - & - & 17.40 & - & - \\
\hline
\end{tabular}

**Validity criteria:

1 Excessive crack curvature

2. Thickness criteria not satisfied

3. Excessive plasticity

4. a/W out of range

5. Non-symmetrical crack front

6. In plane crack propagation

Table 2. Fracture toughness data for $\mathrm{Al} / \mathrm{SiCp}$ and $\mathrm{Al}$ alloys and test validity

As is shown in Table 2, $\mathrm{Al} / \mathrm{SiC}_{\mathrm{p}}$ composites exhibited lower provisional $\mathrm{K}_{\mathrm{Q}}$ values than the reference unreinforced aluminium alloys. In addition, heat treatment processing, and especially T6 treated specimen, had the highest $\mathrm{K}_{\mathrm{Q}}$ values compared to the other two heat treatment conditions. According to the load-displacement curves in Figure 3, composites clearly showed more brittle behaviour than the unreinforced aluminium alloys. T6 heat treated composites have the highest strength, but the lowest ductility compared to the other materials. Although these results provide some insight regarding the fracture behaviour of the materials examined, specific validity criteria have to be satisfied in order to obtain $\mathrm{K}_{\mathrm{IC}}$ values.

\subsection{Examination by infrared thermography}

Nondestructive evaluation techniques are powerful tools for monitoring damage in composite materials [24]. Infrared thermography was used to monitor the plane crack propagation behaviour of particulate-reinforced AMCs $[25,26]$. The deformation of solid materials is almost always accompanied by heat release. When the material becomes deformed or is damaged and fractured, a part of the energy necessary to initiate and propagate the damage is transformed in an irreversible way into heat [26]. The heat wave, generated by the thermo-mechanical coupling and the intrinsic dissipated energy during mechanical loading of the sample, is detected by the thermal camera. By using an adapted detector, thermography records the two dimensional "temperature" field as it results from the infrared radiation emitted by the object. The principal advantage of infrared thermography is its noncontact, non-destructive character. 
A rectangular area on the specimen, located just in front of the initial pre-cracking region, was selected, as shown in Fig. 14a.

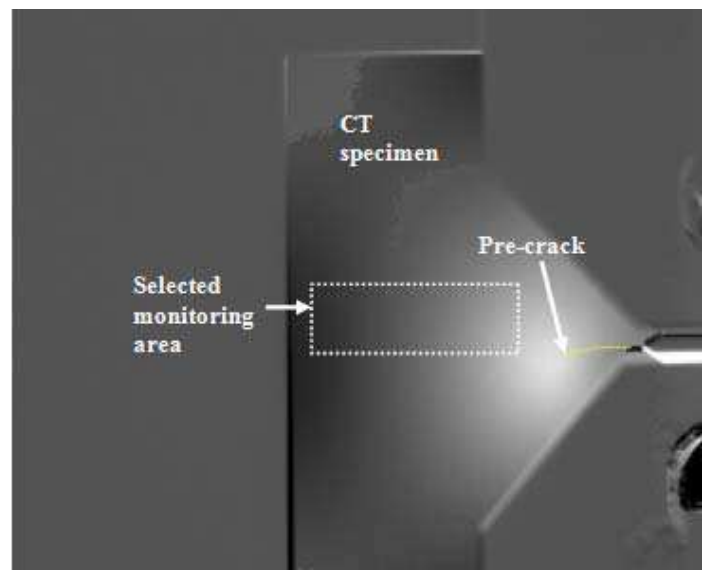

Fig. 14.a CT specimen showing the selected area for thermographic monitoring

The development of fracture was monitored in that area using infrared thermography. The mean temperature in this area versus time during crack growth was calculated using the recorded thermal imprint. As the specimen was stretched in tension, stresses were accumulating in the specimen, and the temperature increased as a function of time. When the accumulated energy became sufficient to propagate the crack, crack growth was observed, resulting in the stress relief. This corresponded to a peak in the temperature-time curve followed by a sudden decrease in temperature. As shown in Fig. 14b, 14c and 14d this behaviour was recurrent until the failure of the specimen. In these figures the thermographic monitoring of Aluminium 2xxx alloy, Al/SiCp T6 composite, and Al/SiCp HT1 composite samples is presented respectively. The different stages of crack growth for each material up to the final fracture of the specimen can be clearly observed. Just prior to fracture, the plasticity zone was clearly delineated on the specimen's surface as a heated region, which may be readily attributed to local plastic deformation. Furthermore, as seen in all figures, the crack was propagated in-plane throughout the experiment.

A comparison of the thermography graphs in Figs. 14b, 14c, and 14d leads to the conclusion that the aluminium alloy exhibited different crack propagation behaviour than the $\mathrm{Al} / \mathrm{SiCp}$ composites. For the aluminium alloy, the temperature versus time curve in Fig. 5b showed extended plasticity behaviour before final fracture occurred. This behaviour was evidenced by the constant increase in temperature between the temperature picks at the 60th and 140th second (figure 14b). This behaviour may be attributed to the small specimen thickness. However, for the T6 heat treated composite material in Fig. 14c, fracture was more elastic as the multiple temperature peaks indicated a confinement of the plasticity zone. Also, plasticity was formed in a more balanced way regarding the overall fracture process. It was also observed that T6 heat treated composites exhibited fewer picks compared to the HT1 heat treated specimens (Fig. 14d). This was attributed to the presence of a stronger interface in the T6 material as the accumulation of precipitates near the interface, resulted in the improvement of the fracture toughness of the material. 


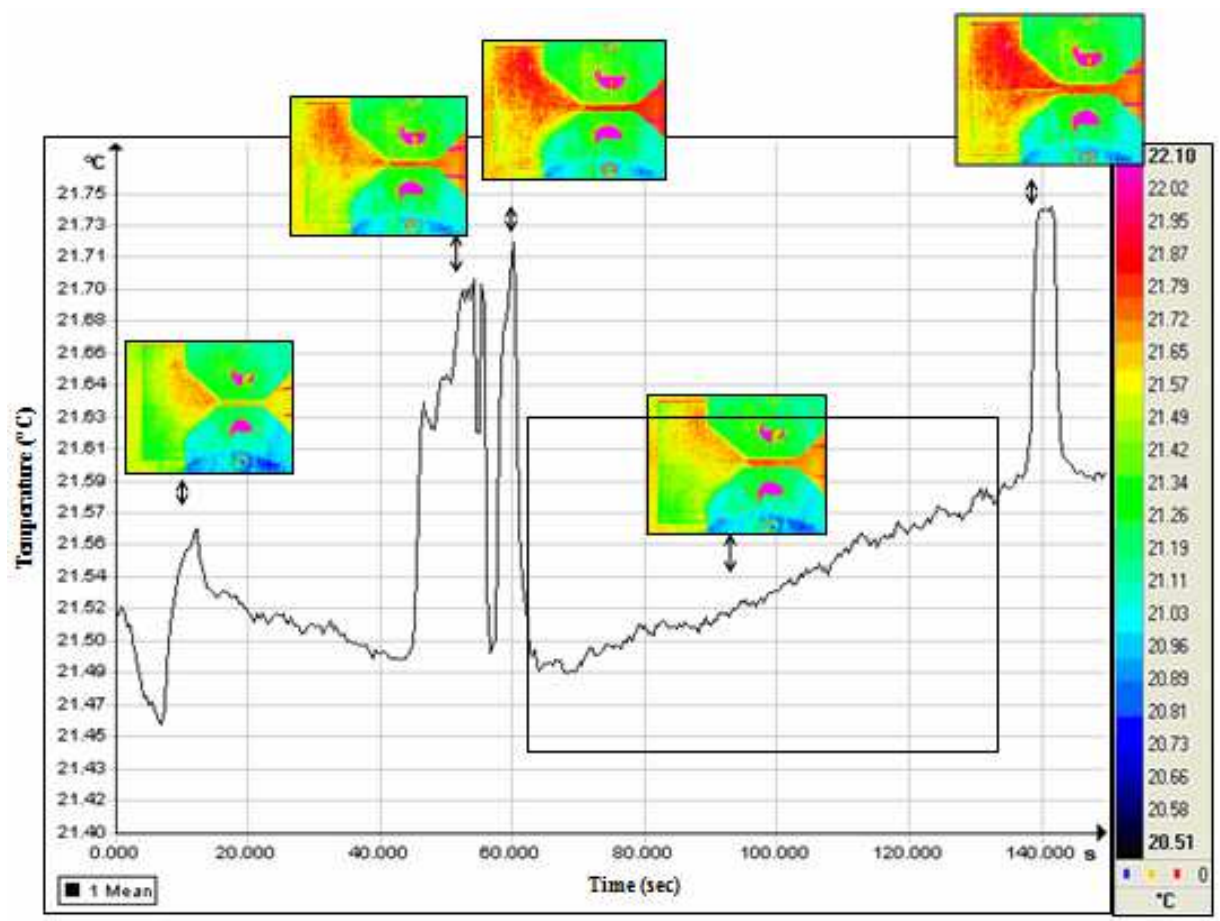

(b)

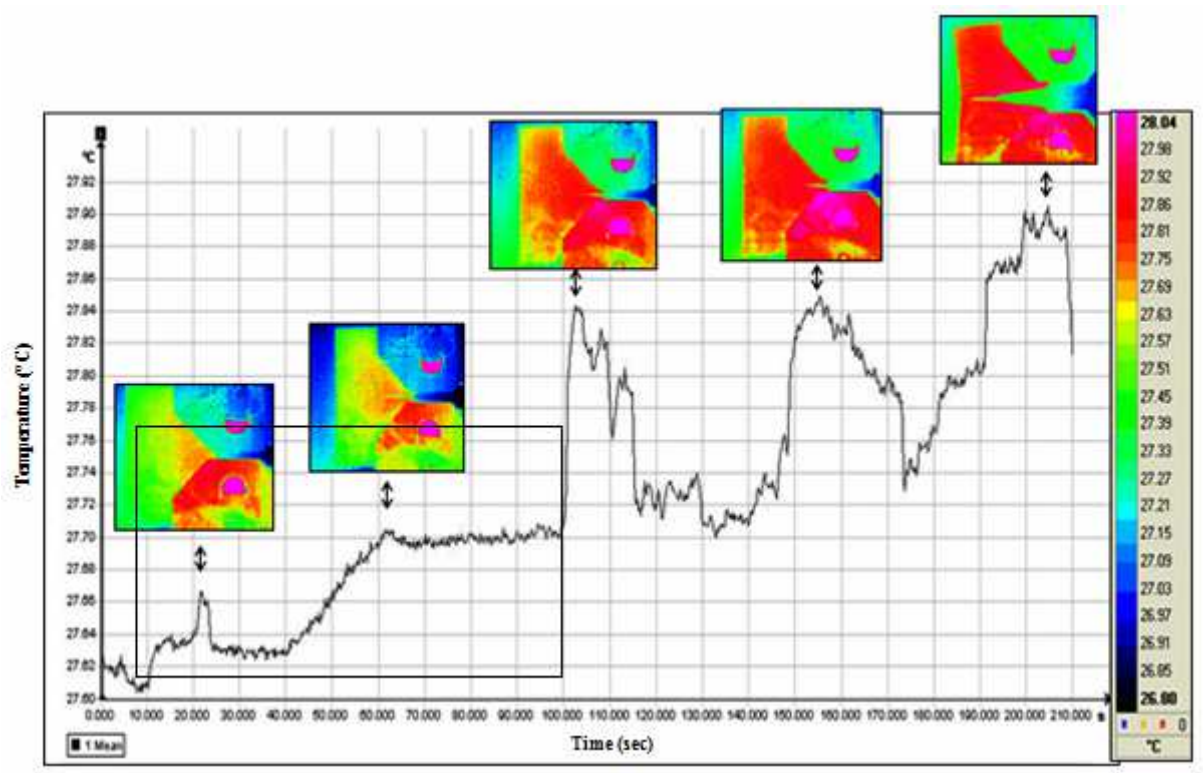

(c) 


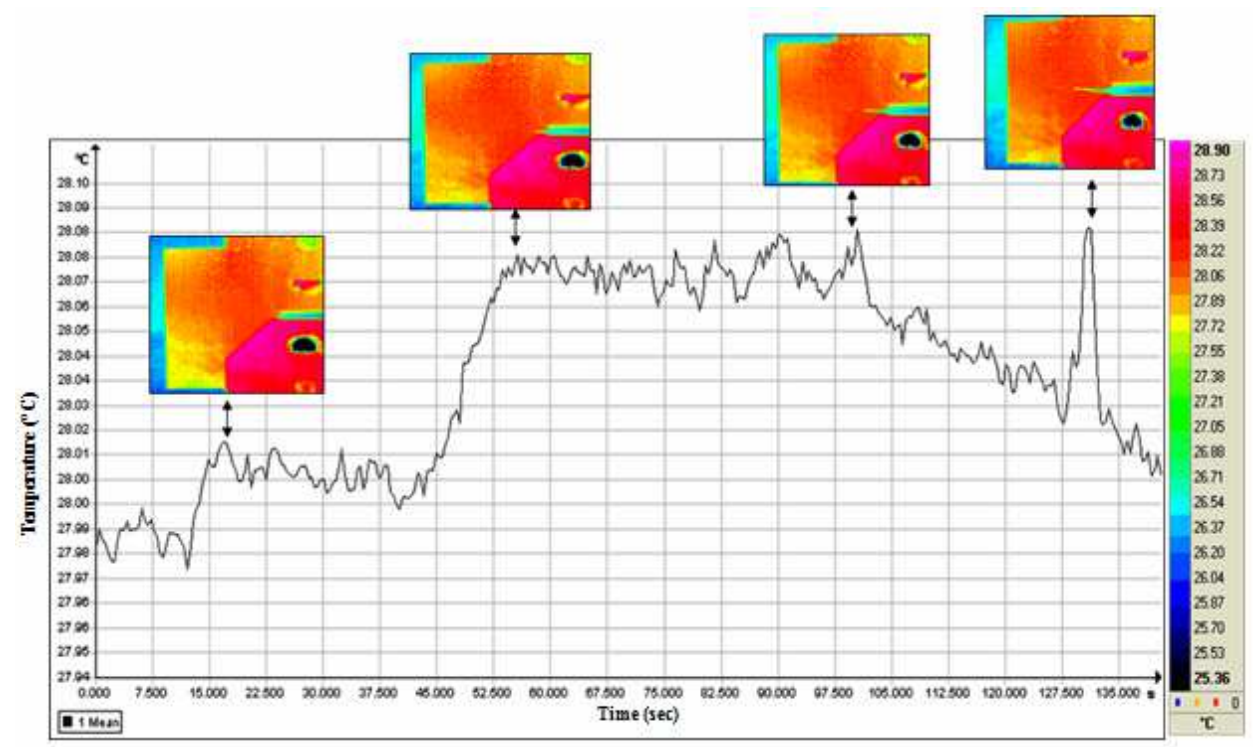

(d)

Fig. 14. Thermographic monitoring of various CT specimens showing the different stages of crack growth up to the specimen's final fracture: (b) Aluminium 2xxx, (c) Al/SiCp T6 composite, (d) Al/SiCp HT1 composite

\subsection{A model for predicting interfacial strengthening behaviour of particulate reinforced AMCs}

A model proposed by McMahon and Vitek [27] predicts the fracture resistance of a ductile material that fails by an intergranular mechanism. Based on this model, an effective work parameter can be developed to predict fracture strength of an interface at a segregated state using Griffith crack-type arguments. The Griffith's equation, which was derived for elastic body, is applied here because it is assumed that the yielding zone size ahead of the crack is small enough and the fracture is governed by the elastic stress field. The model further assumes that small changes in interfacial energy caused by segregation of impurities at the interface will result in a much larger change in the work of fracture. This is due to the fact that the work of fracture must be provided by a dislocation pile-up mechanism around the advancing crack-tip on the interface. This implies that additional work must be provided to deform the material at the crack-tip in addition to the work needed to overcome the interface energy and to replace it with two surfaces. The definition of interfacial fracture strength, $\sigma_{\text {int }}$, is then given by:

$$
\sigma_{\text {int }}=\sqrt{\frac{100 \varepsilon_{P} E_{\text {int }}}{\pi d}}
$$

where,

E is Young's modulus, $d$ is the particle thickness, since it is assumed that cracks of the order of the particle size are present when considering crack propagation through the interface 
and the particulate, $\varepsilon_{\mathrm{p}}$ is the energy required to create two fracture surfaces $=2 \varepsilon_{\mathrm{s}}-\varepsilon_{\mathrm{gb}}\left(=\varepsilon_{\mathrm{o}}\right)$, with $\varepsilon_{\mathrm{s}}$, the surface energy, and $\varepsilon_{\mathrm{gb}}$, the grain boundary energy.

The $100 \varepsilon_{\mathrm{p}}$ component allows for dislocation interaction and movement ahead of the cracktip in ductile materials. This refers to the work required for a total separation of the lattice planes, which is equal to the area under the force-extension curve.

From equation (6) $\mathrm{ep}$ can be estimated if Kint (Interface fracture toughness) and Eint (Interface Young's Modulus) are known.

$$
\frac{K_{\mathrm{int}}^{2}}{100 E_{\mathrm{int}}}=\varepsilon_{p}\left(1-\frac{\mathrm{ZRT} \ln (1-c+B c)}{\varepsilon_{p}}\right)^{n}
$$

Where,

$\mathrm{Z}$, describes the density of interface sites which are disordered enough to act as segregation sites $\left(=\mathrm{D} \rho_{\mathrm{S}}\right)$, with $\mathrm{D}$ the thickness of the interface region, and $\rho_{\mathrm{S}}$ the density of the interface region $(D=300 \mathrm{~nm})\left(\rho=2.6889 \mathrm{~g} / \mathrm{cm}^{3}\right.$ for Aluminium and $3.22 \mathrm{~g} / \mathrm{cm}^{3}$ for $\left.\mathrm{SiC}\right)$,

$\mathrm{R}$, is the gas constant $(=8.314472(15) \mathrm{J} \bullet \mathrm{K}-1 \bullet \mathrm{mol}-1)$,

$\mathrm{T}$, is the absolute temperature $(=803.15 \mathrm{~K}$ for $\mathrm{T} 6,=723.15 \mathrm{~K}$ for HT1 $)$,

C, is the segregate concentration needed to cause embrittlement ( $=0.1$ for pure aluminium),

$\mathrm{B}$, describes the modification of the boundary energy by impurities using the Zuchovitsky equations,

$\mathrm{n}$, is the work hardening exponent (= 10 for FCC aluminium).

In hard particle reinforced metal matrix composites the stress transfer from the matrix to the particles is mainly controlled by the misfit of the elastic constants between the two phases [28]. To measure the stress transfer to the particle, in an homogeneous material subjected to tensile loading, the stress carrying capability of the particle is defined as the ratio of the normal stress $\sigma_{\mathrm{N}}$ to the particle in the loading direction to the macroscopic tensile stress, $\sigma_{\mathrm{T}}$, i.e. the ratio $L=\sigma_{N} / \sigma_{\mathrm{T}}$. By using Eshelby's theory, the stress carrying capability of a spherical inhomogeneity can be written as [29]:

$$
L=\frac{9 x(2+3 x)}{(1+2 x)(8+7 x)}
$$

where, $x=E_{i} / E_{m}$, and $E_{i}$ and $E_{m}$ are Young's moduli for inhomogeneity and matrix, respectively.

Furthermore, the shear lag model, originally developed by Cox [30] modified by Llorca [31], can be used to estimate the stress carrying capability of a particulate, assuming that the volume fraction of reinforcement is small and the average stress in the matrix is approximately equal to the applied stress:

$$
L=1+\frac{a}{\sqrt{3}}
$$

where $a=\bar{h} / 2 \bar{r}$ is the aspect ratio of the reinforcement, with $\bar{h}$ and $\bar{r}$ the average length and the average diameter of the particle.

A model has been proposed to estimate the effects of particle volume fraction on fracture toughness in SiC particle-reinforced aluminium alloy matrix composites. This model assumes that $\mathrm{SiC}$ particles are uniformly distributed in the matrix and that the pattern of 
particle distribution is similar to FCC structure in metals. The fracture toughness of the composite can then be written as [32]:

$$
K_{I C}=\frac{K_{p}}{L_{p}} V_{m}^{\prime}+\frac{2 K_{\text {int }}}{L_{p}+L_{m}}\left(V_{m}-V_{m}^{\prime}\right)+\frac{K_{m}}{L_{m}} 2 V_{m}+K_{m}\left(1-3 V_{m}\right)
$$

where $\mathrm{K}_{\mathrm{IC}}, \mathrm{K}_{\mathrm{p}}=3 \mathrm{MPa} \mathrm{m}-1 / 2, \mathrm{~K}_{\mathrm{m}}=35 \mathrm{MPa} \mathrm{m}-1 / 2$, and $\mathrm{K}_{\text {int }}$ is the fracture toughness of the composite, $\mathrm{SiC}$ particulates, A359 aluminium alloy matrix, and interface, respectively. $\mathrm{L}_{\mathrm{p}}$ and $\mathrm{L}_{\mathrm{m}}$ are the stress carrying capabilities of a particulate and the matrix, respectively. On average, for $\mathrm{SiC}$ particles and aluminium alloy matrix, $\mathrm{L}_{\mathrm{p}} \sim \mathrm{L}_{\mathrm{m}} \sim 2$. The value of $\mathrm{L}_{\mathrm{m}}=1$ is applicable for clean surfaces. However, due to processing conditions and the physical interaction at the matrix/reinforcement interface the interface contains partially contaminated surfaces, therefore $\mathrm{L}_{\mathrm{m}}=2$ since it cannot be considered as a "clean surface". $\mathrm{V}_{\mathrm{m}}$ and $\left(\mathrm{V}_{\mathrm{m}}-\mathrm{V}_{\mathrm{m}}^{\prime}\right)$ are the area fractions for particle cracking and interface failure, respectively. These area fractions though are not accurately known. However Wang and Zhang [33] found that the ratio of particle cracking over interface failure $\mathrm{V}_{\mathrm{m}} /\left(\mathrm{V}_{\mathrm{m}}-\mathrm{V}_{\mathrm{m}}^{\prime}\right)$ was about $0.13(=1.4 \% / 10.7 \%)$ in a $\mathrm{SiC}$ particle-reinforced aluminium alloy composite.

Young's modulus of matrix has been obtained for A359 aluminium matrix. The particles $E_{p}$, matrix $E_{m}$, and interface $E_{i}$ shown in equation

$$
E_{C}=E_{p} v_{f}^{2 / 3}+E_{m}\left(1-V_{f}^{\prime 2 / 3}\right)+E_{i}\left(V_{f}^{\prime 2 / 3}-V_{f}^{2 / 3}\right)
$$

Due to the fact that the difference $\left(V_{f}^{\prime}-V_{f}\right)$ is very small, a good approximation is to consider that the Young's modulus of the interface region is close to that of the matrix; $E_{i} \cong E_{m}$ [32].

The parameter $B$ describes the modification of the boundary energy by impurities using the Zuchovitsky equations [34, 35], given by:

$$
B=e^{\left(\frac{\varepsilon_{1}-\varepsilon_{2}}{R T}\right)} \cong e^{\left(\frac{0.75 \varepsilon_{F}}{R T}\right)}
$$

where $\varepsilon_{2}-\varepsilon_{1}$ is the difference between the formation energy in the impurity in the bulk and the interface region. It is assumed that the values of the surface energy and the impurity formation energy in the bulk are close, and therefore the numerator in the exponential term depends on the impurity formation energy in the interface region, which is assumed to be $0.75 \varepsilon_{\mathrm{f}}$, where $\varepsilon_{\mathrm{f}}$ is the formation energy of the impurity in the bulk.

Using Faulkner's approach [36], to the derivation of impurity formation energy,

$$
\varepsilon_{\mathrm{f}}=\varepsilon_{\mathrm{S}}+\varepsilon_{\mathrm{e}}
$$

where, $\varepsilon_{\mathrm{s}}$ is the surface energy required forming the impurity atom and $\varepsilon_{\mathrm{e}}$ is the elastic energy involved with inserting an impurity atom into a matrix lattice site. This is given by:

$$
\varepsilon_{f}=\frac{0.5 \varepsilon_{S}}{1.94}+\frac{8 \pi G}{3 e} a_{m}\left(a_{i}-a_{m}\right)^{2} e V
$$

where,

$\varepsilon_{\mathrm{S}}$ is the surface energy $(1.02 \mathrm{~J} \mathrm{~m}-2)$ 
e is the electronic charge $\left(1.60217646 * 10^{\wedge} 19\right.$ Coulomb)

$\mathrm{a}_{\mathrm{i}}$ is the impurity atomic radius $(0.118 \mathrm{~nm}$ for $\mathrm{Si})$

$\mathrm{a}_{\mathrm{m}}$ is the matrix atomic radius ( $0.143 \mathrm{~nm}$ for aluminium)

$\mathrm{G}$ is the shear modulus (26 GPa for aluminium)

By performing the calculations the impurity formation energy, $\varepsilon_{\mathrm{f}}$, for A359 aluminium alloy (Al-Si-Mg) can be determined and then substituted in equation (11) to calculate B.

The micro-mechanics model described above is based on thermodynamics principles and is used to determine the fracture strength of the interface at a segregated state in aluminium matrix composites. This model uses energy considerations to express the fracture toughness of the interface in terms of interfacial critical strain energy release rate and elastic modulus. The interfacial fracture toughness is further expressed as a function of the macroscopic fracture toughness and mechanical properties of the composite, using a toughening mechanism model based on stress transfer mechanism. Mechanical testing is also performed to obtain macroscopic data, such as the fracture strength, elastic modulus and fracture toughness of the composite, which are used as input to the model. Based on the experimental data and the analysis, the interfacial strength is determined for SiC particlereinforced aluminium matrix composites subjected to different heat treatment processing conditions and the results are shown in table 2 . It is observed that $K_{\text {int }}$ values are close to the $\mathrm{K}_{1 \mathrm{c}}$ values of the composites. Furthermore, $\sigma_{\mathrm{int}}$ values found to be dependent on the heat treatment processing with $\mathrm{T} 6$ heat treatment composite obtain the highest interfacial fracture strength.

\subsection{Fatigue testing and crack growth behaviour}

Tension-tension fatigue tests were conducted using a hydraulic testing machine. The system was operated under load control, applying a harmonic tensile stress with constant amplitude. By specifying the maximum and the minimum stress levels, the other stress parameters could be easily determined. These were the stress range, $\sigma_{r}$, stress amplitude, $\sigma_{a}$, mean stress, $\sigma_{\mathrm{m}}$, and fatigue stress ratio, $\mathrm{R}\left(=\sigma_{\mathrm{min}} / \sigma_{\mathrm{max}}\right)$. Throughout this study, all fatigue tests were carried out at a frequency of $5 \mathrm{~Hz}$ and at a stress ratio $\mathrm{R}=0.1$. Different stress levels between the ultimate tensile strength (UTS) and the fatigue limit were selected, resulting in so-called Wöhler or S-N curves. Tests exceeding $10^{6}$ cycles without specimen failure were terminated. Specimens that failed in or close to the grips were discarded. The geometry of the samples was the same as those used for the tensile characterisation, i.e. rectangular strips of $12.5 \mathrm{~mm}$ width, and $1.55 \mathrm{~mm}$ thickness.

The normalised "S-N" curves of the fatigue response of the $\mathrm{Al} / \mathrm{SiC}$ composites is shown in Fig. 15. The stress was normalised over the UTS of each material and plotted against the number of cycles to failure. As can be observed, whereas in the untreated T1 condition the composite retains at least $85 \%$ of its strength as fatigue strength, the corresponding value for the T6 heat treatment is falling to the $70 \%$ of UTS. The HT1 heat treatment is exhibiting an intermediate behaviour, with its fatigue strength falling to $75 \%$ of the corresponding UTS value. It can be concluded that aggressive heat treatment reduces the damage tolerance of the composites.

A direct comparison of the fatigue performance of the composite with the corresponding quasi static performance in tension reveals that the T6 heat treatment improved the strength of the composite. This can be attributed to a dominant mechanism related to the changes in the microstructure of the composite. This mechanism relates to the precipitations appearing 
in the microstructure of the composite at the vicinity of the interphase area, which results to the composite hardening. The creation of the interphase together with the improved stress transfer may be regarded as the main contributing parameters to the improved mechanical properties of the particulate reinforced composite. The improved static strength is followed by a less spectacular performance in fatigue, with the fatigue limit of the material falling to the $70 \%$ of the UTS.

SN Curve Al/SiC 20\%

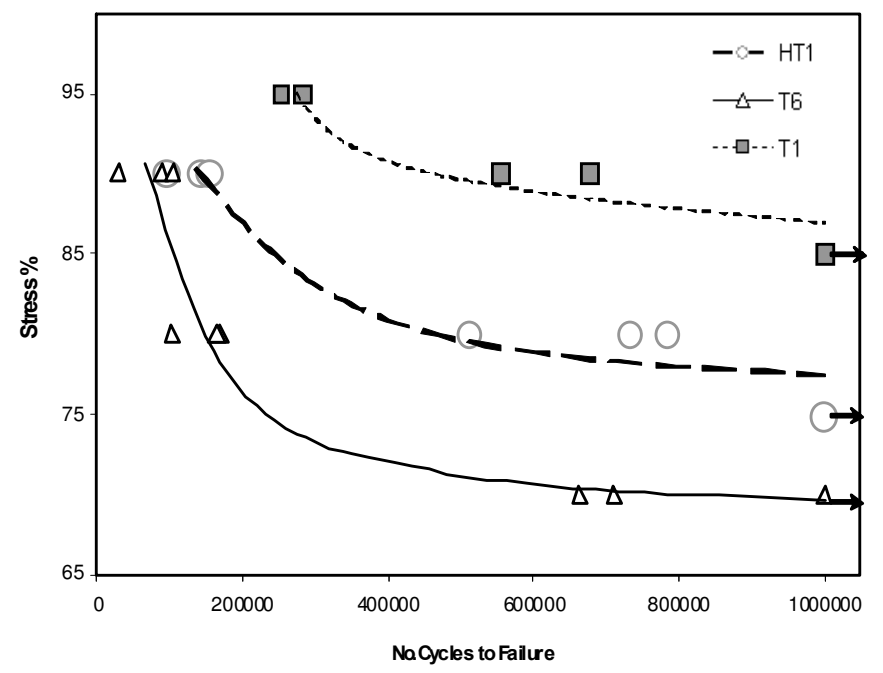

Fig. 15. S-N Curve of $\mathrm{Al} / \mathrm{SiC} 20 \%$ Composite

\subsubsection{Crack growth rate vs. range of stress intensity}

To study the crack growth rate $(\mathrm{da} / \mathrm{dN})$ vs. stress intensity range $(\Delta \mathrm{K})$ data for aluminium $\mathrm{SiC}_{\mathrm{p}}$ composites and aluminium $2 \times x x$ series specimens, the materials were subjected to cyclic loading. Fatigue crack growth tests were conducted according to the ASTM E647 standard using a servo hydraulic testing machine. The tests were conducted under load control. Compact tension (CT) specimens were prepared for the fatigue crack growth experiments. The fatigue tests for the monolithic aluminium specimens were performed at a standard frequency of $5 \mathrm{~Hz}$. However, a lower frequency of $1 \mathrm{~Hz}$ was selected for the composite specimens in order to minimize the effect of sudden failure due to the brittle nature of these materials. The experiments were performed at a load ratio $\mathrm{R}=0.25$ and maximum load ranges of $3.7-4.5 \mathrm{KN}$, keeping the maximum stress at about $70 \%$ of the material's ultimate tensile strength.

The technique used for determining the crack growth rate versus stress intensity range during the cyclic loading tests was based on non-contact monitoring of the crack propagation by lock-in thermography. This new technique deals with mapping the crack growth nondestructively. Lock-in thermography is based on remote full field monitoring of thermal waves generated inside the specimen by cyclic loading that caused an oscillating temperature field in the stationary regime. Lock-in refers to the necessity for monitoring the 
exact time dependence between the output signal (thermal wave) and the reference input signal (fatigue cycle). This is done with a lock-in amplifier so that both phase and magnitude images become available.

The detection system included an infrared camera. The camera was connected with the lockin amplifier, which was then connected to the main servo hydraulic controller. Therefore, synchronization of the frequency through the lock-in amplifier and the mechanical testing machine could be achieved and lock-in images and data capture during the fatigue testing were enabled.

The camera was firstly set at a distance close to the specimen, in order to have the best possible image capture. Then, the fatigue pre-cracking started while synchronizing, at the same frequency, fatigue cycles and infrared camera through the lock-in amplifier.

In order to determine the crack growth rate and calculate the stress intensity factor using thermographic mapping of the material undergoing fatigue a simple procedure was used:

a. The distribution of temperature and stresses at the surface of the specimen was monitored during the test. Therefore, thermal images were obtained as a function of time and saved in the form of a movie.

b. The stresses were evaluated in a post-processing mode, along a series of equally spaced reference lines of the same length, set in front of the crack-starting notch. The idea was that the stress monitored at the location of a line versus time (or fatigue cycles) would exhibit an increase while the crack approaches the line, then attain a maximum when the crack tip was on the line. Due to the fact that the crack growth path could not be predicted and was not expected to follow a straight line in front of the notch, the stresses were monitored along a series of lines of a certain length, instead of a series of equally spaced points in front of the notch. The exact path of the crack could be easily determined by looking at the stress maxima along each of these reference lines.

Four lines of the same length, equally spaced at a distance of $1 \mathrm{~mm}$, were set on the thermal images of the CT specimen at a distance in front of the specimen's notch.

In Figure 16, the crack growth rate for the heat treated composite specimens and the reference aluminium alloy samples are plotted on a logarithmic scale as a function of the stress intensity range. The results showed that the heat treatment processing influences crack growth behaviour of the composite materials. Specimens subjected to T6 heat treatment condition exhibited the highest crack growth rate vs. stress intensity range slope compared to the other composite systems. Moreover, the crack growth rate vs. stress intensity range line of specimens subjected to T6 heat treatment was shifted towards higher $\Delta \mathrm{K}$ values compared to that from specimens subjected the other two heat treatment conditions. This implies that in order to attain the same crack growth rate, higher stress intensity factor is required for specimens subjected to T6 condition compared to those subjected to T1 and HT-1 conditions. The need for higher stresses for a crack to propagate reveals the material's microstructural strength, where micro-mechanisms such as precipitation hardening promote high stress concentrations at the crack tip, resulting in the toughening of the crack path. The above postulations agree with previews results, where the T6 heat treated composites showed superior strength but the lowest ductility compared to T1 or HT-1 heat treated specimens. Results, shown in Figure 16, indicate that at intermediate values of crack growth rate $\left(10^{-2}\right.$ to $10^{-5} \mathrm{~mm} /$ cycle $)$ the $\mathrm{Al} / \mathrm{SiCp}$ composites have fracture properties comparable to those of the unreinforced matrix alloys. It is obvious that in these composites crack propagation rate seems more balanced and takes more time than the aluminium alloy obtaining crack growth rate values from around $10^{-1}$ to $10^{-4} \mathrm{~mm} /$ cycle. 


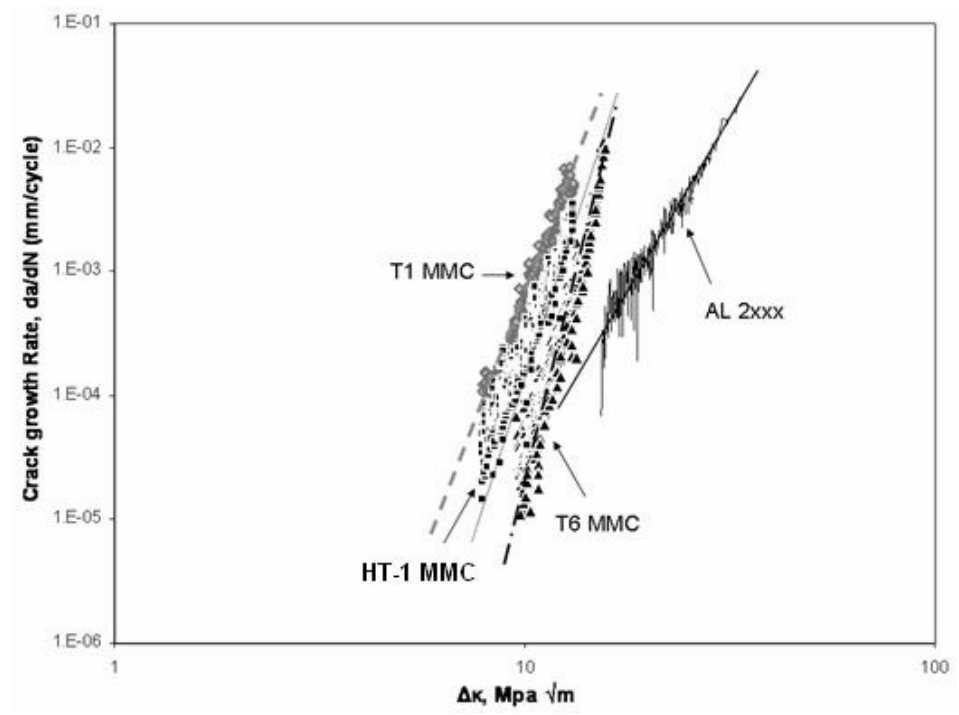

Fig. 16. da/dN vs. $\Delta \mathrm{K}$ plots of $\mathrm{Al} / \mathrm{SiCp}$ composite and monolithic aluminum $2 \mathrm{xxx}$ specimens

\subsubsection{Estimation of da/dN vs. $\Delta \mathrm{K}$ using thermography and compliance methods}

Using the procedure described above based on thermographic mapping, the local stress versus time was measured for the $\mathrm{T} 6$ heat treated $\mathrm{Al} / \mathrm{SiCp}$ along each of the four reference lines placed in front of the CT specimen's notch. The maximum value of stress versus the number of fatigue cycles was then plotted for those four lines (Figure 17). As expected, Figure 17 shows that the local stress, monitored at the location of each line, increases as the crack is approaching that line, then attains a maximum when the crack tip is crossing the line. Finally, after the crack has crossed the line, the local stress measured at the location of the line decreases. This is also expected, since the stress values shown in Figure 17 are stress maxima from all the locations along the particular line. At the exact position on a line where the crack has just crossed, the local stress is null as expected.

From the stress maxima versus fatigue cycles curves, for each reference line, shown in Figure 17, the crack lengths versus the number of fatigue cycles were determined for A359/ $\mathrm{SiC}_{\mathrm{P}}$ composites in all three different thermal treatment conditions: T1, T6, and HT-1 (Fig. 18). As it is shown in Figure 18, the crack growth rate was found to be quite linear for all heat treatments. Also, there is a small change in the linear slope for the HT-1 heat treated sample, showing increased ductility, which indicates that more time (i.e. cycles) is needed for the crack to grow in this case. For the T6 heat treatment, the results depict a brittle behaviour, as the crack starts to grow earlier than in the other two cases, supporting evidence of brittle fracture.

The stress intensity range was further calculated by the data shown in Figure $17 . \Delta \mathrm{K}$ values have been estimated from the stress maxima versus fatigue cycles curves for each reference line, shown in Figure 17. Each of the four lines provides a stress intensity range and a $\mathrm{da} / \mathrm{dN}$ value. The data obtained using lock-in thermography, shown in Figures 18 and 19, were correlated with crack growth rate values obtained by the conventional compliance method and calculations based on the Paris law. Furthermore, the da/dN vs. $\Delta \mathrm{K}$ curves 
steaming from the compliance method were plotted in the same graph, for comparison purposes, with those obtained using lock-in thermography (Fig. 20). It can be seen in Figure 20 that the two different methods are in agreement, demonstrating that lock-in thermography is a credible nondestructive method for noncontact evaluation of the fracture behaviour of materials.

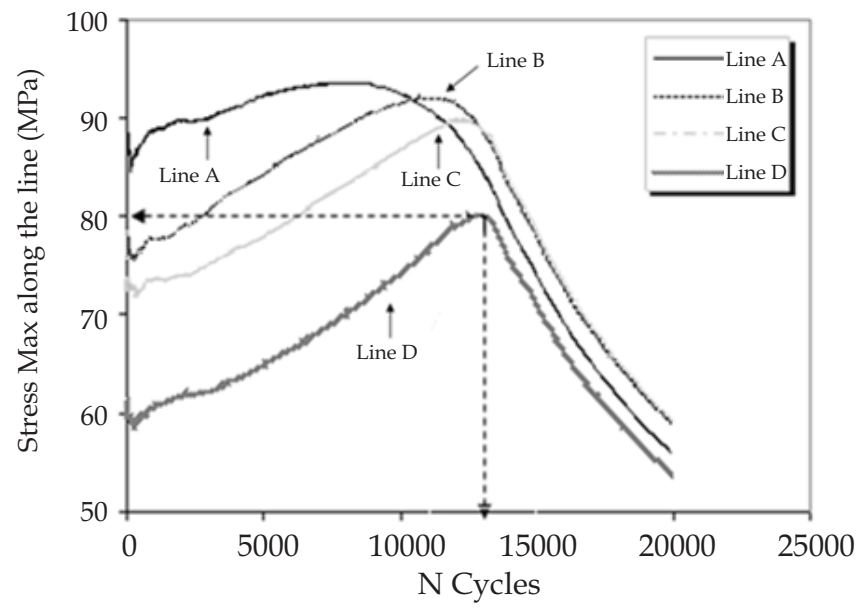

Fig. 17. T6 al/SiCp stress maxima along the four reference lines vs. number of fatigue cycles

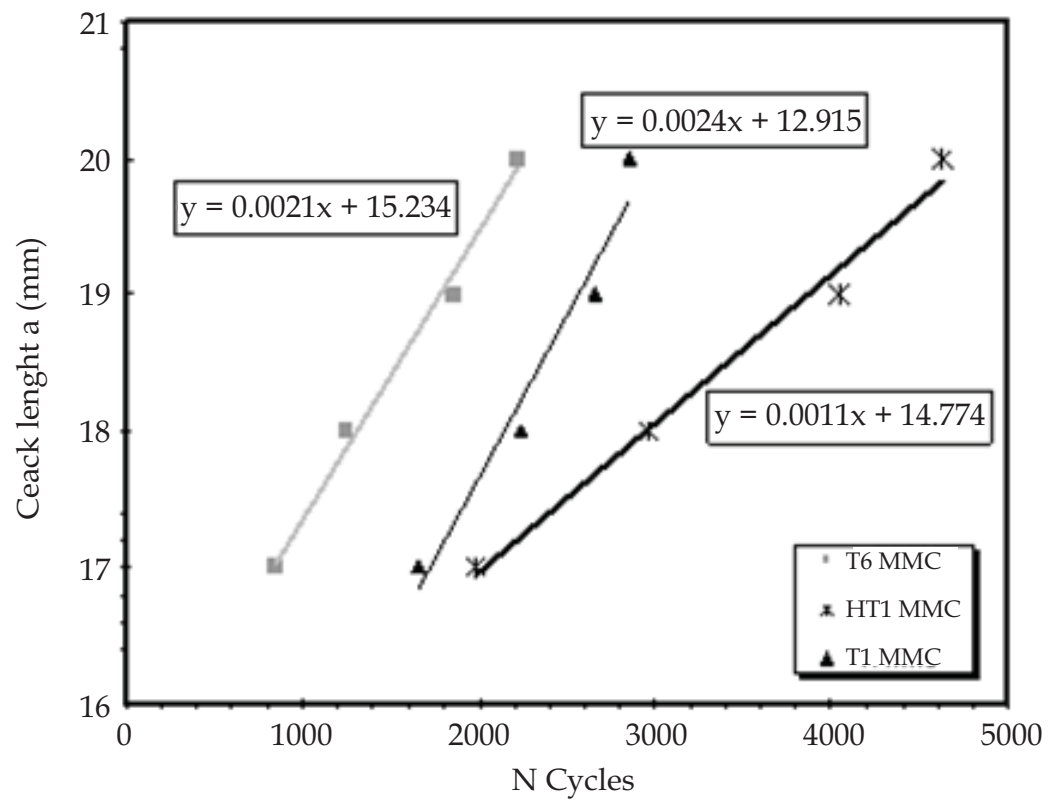

Fig. 18. Crack length vs. cycles obtained from lock-in thermography data for A359/SiCp composites subjected to three different heat treatment conditions 


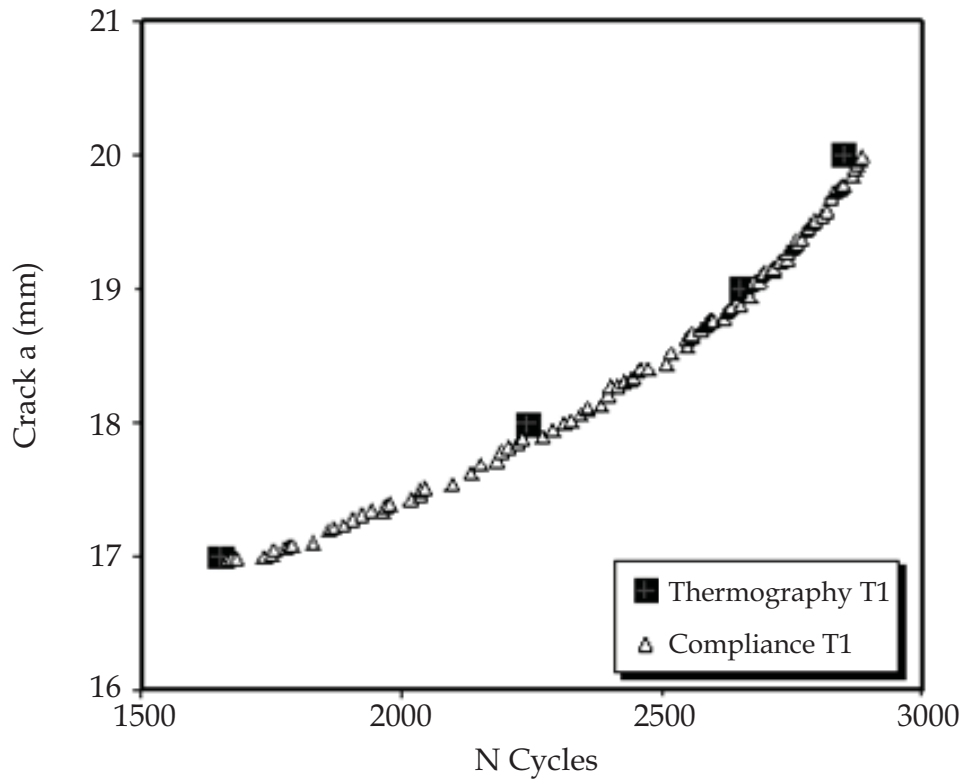

Fig. 19. Crack growth rate determined by compliance vs. thermography for A359/SiCp composite

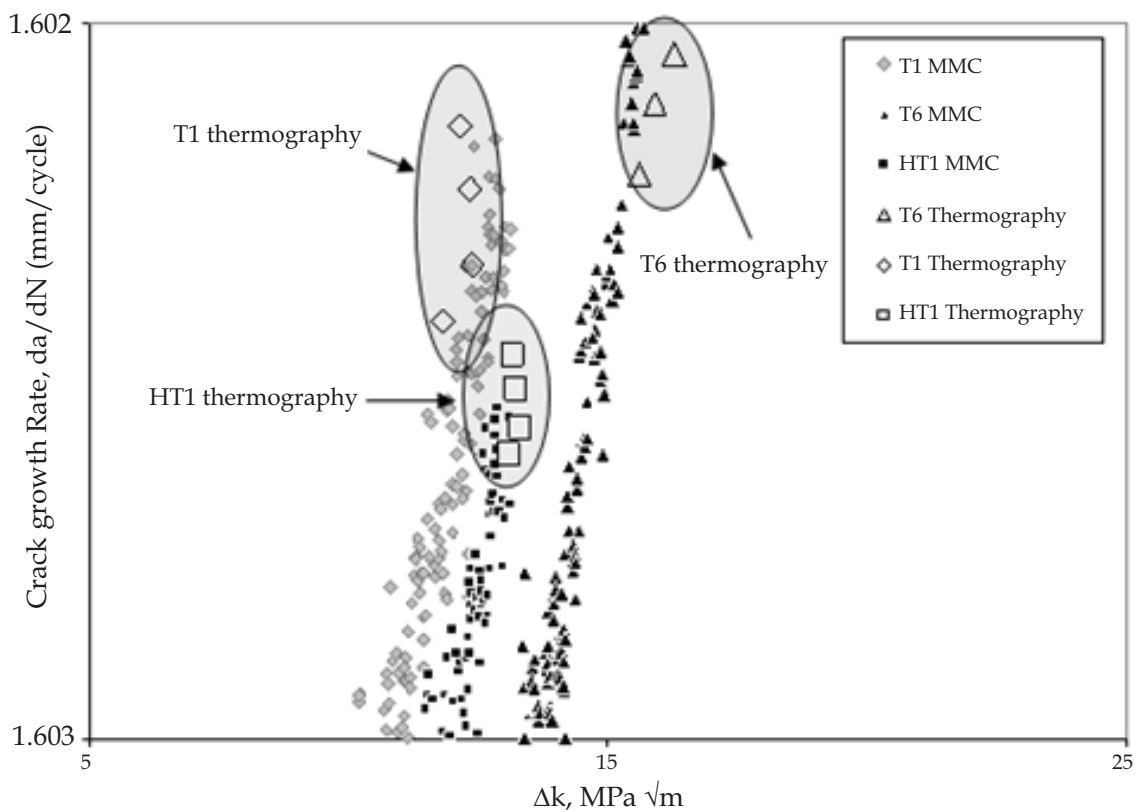

Fig. 20. da/dN vs. $\Delta \mathrm{K}$ for $\mathrm{Al} / \mathrm{SiCp}$ specimens - Thermography vs. Compliance method 


\section{Aluminium honeycomb sandwich panels and metallic foam}

\subsection{Material and experimental procedure}

The compact tension specimens were manufactured from rectangular plates conforming to BS 7448-1: 1991 as shown in Fig. 21.

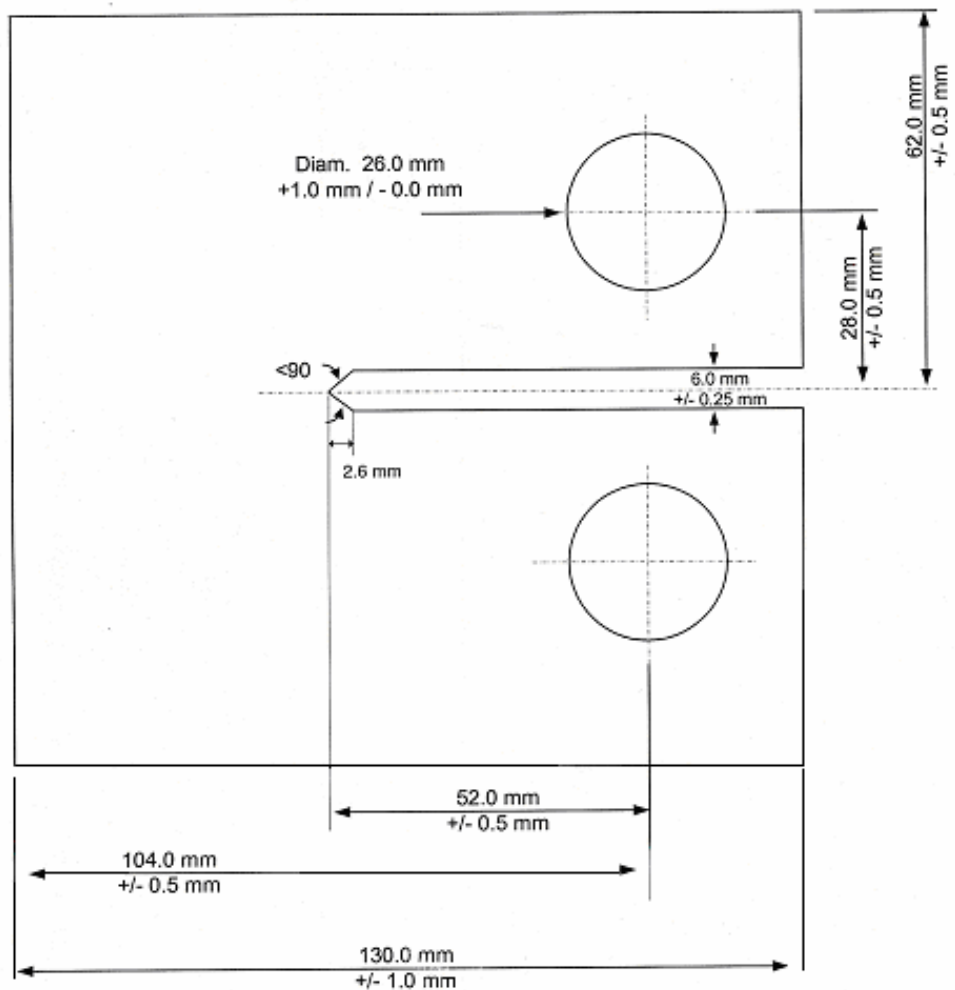

Fig. 21. Compact tension specimen

The fatigue tests were performed on a standard Mayes machine attached to a Pd system. The Pd system was switched on with the current circulating for 30 minutes before any readings were taken; the fatigue cycle was then begun. Data from the Pd system was exported into an excel spreadsheet and the number of cycles versus crack propagation was then plotted. From these results, values of stress intensity $(\Delta K)$ versus crack growth rate were then calculated. In order to calculate the stress intensity factor, a standard equation was used.

$$
\Delta K=\frac{\Delta P Y}{B \sqrt{W}}
$$

Where, $Y=$ geometry factor, $\Delta P=$ change in cyclic load $\left(P_{\max }-P_{\min }\right), B=$ sample thickness and $W=$ sample width. Fatigue tests were conducted in fully tension - tension and at a constant frequency. 


\subsection{Results and discussion}

The results of fatigue testing of aluminium honeycomb sandwich panel both in air and in $3.5 \%$ sodium chloride solution, are plotted in Figure 22. A total of twenty cyclic deformation tests were conducted in fully tension-tension at a constant frequency of $2 \mathrm{HZ}$, which is equivalent to two cycles per second. The results of fatigue testing of metallic foam sandwich panel both in air and in 3.5\% sodium chloride solution, are plotted in Figure 23.

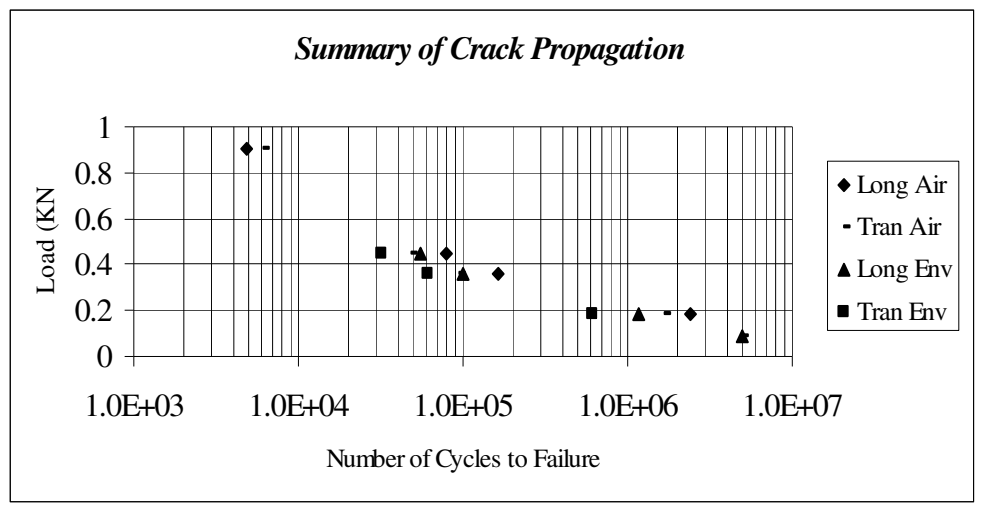

Fig. 22. Aluminium honeycomb fatigue data

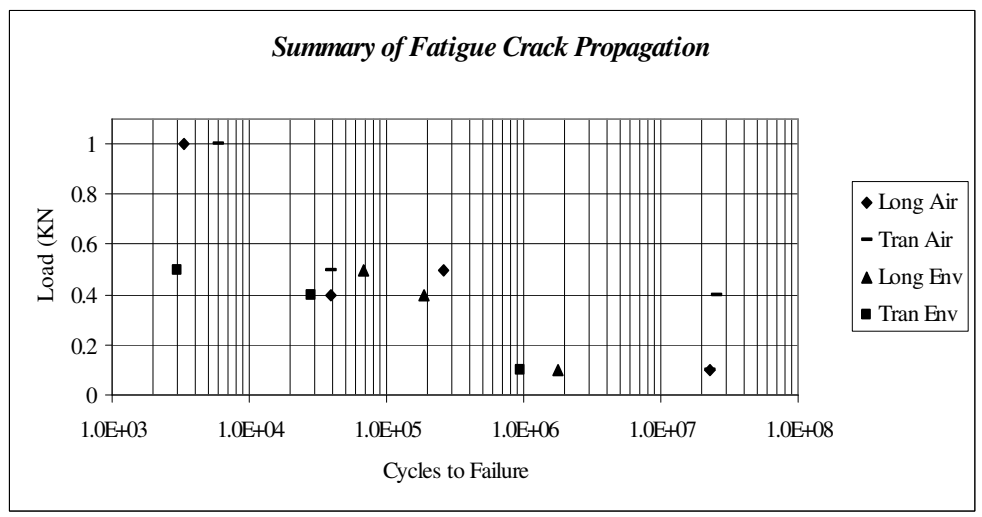

Fig. 23. Metallic foam fatigue data

\subsubsection{Aluminium honeycomb}

Cyclic deformation data reveals that honeycomb sandwich panel samples do produce consistent results with acceptable repeatability of results even though the honeycomb core is not a conventional structure due to its complex geometry, but because of its homogeneity, it does compare well to the consistent results we would expect from a less complex conventional aluminium solid sample. The results, also, revealed that samples taken from a longitudinal direction constantly have a longer life expectancy, of approximately $40 \%$, then those samples taken from a transverse direction regardless of environmental exposure. 
Plotting of fatigue data versus stress intensity for aluminium honeycomb sandwich panels shows that samples tested in a corrosive environment are inferior in performance when compared to samples tested in air. Evidence from crack propagation testing establishes that crack propagation takes place, firstly, within the side plate, leading to some fracture but mainly tearing of the honeycomb structure, only a small amount of crack propagation is evident in the honeycomb structure. The weakest part of the sandwich panel structure appears to be the interface between the aluminium side plate and honeycomb core, with the adhesive used being epoxy resin. Crack propagation testing shows that crack growth is not equal on both sides of the sandwich panel structure; this effect must be due to the complex geometry of the hexagonal core and is a potential difficulty when considering the commercial applications of the aluminium honeycomb sandwich panels.

This research produces a valid method of calculating the Paris exponent, $\mathrm{m}$, with the aluminium honeycomb sandwich panel having a Paris exponent, $\mathrm{m}$, of 1.9. This value is similar when compared to typical values for aluminium alloys of between 2.6 to 3.9.

\subsubsection{Metallic foam}

Examination of the metallic foam sandwich panel revealed that a consistent form of failure could not be established, with size and position of voids within the metallic foam core having a detrimental effect on failure. Cyclic deformation data revealed that samples tested in air produced inconsistent results showing that the voids within the metallic foam play an important part in crack propagation. However, when samples are tested in an environment, samples taken from the longitudinal direction are superior. This leads to the conclusion that in an environment precipitates within the outer skin have a significant effect on crack propagation. The crack deformation data suggests that due to the complexity of the metallic foam structure and the scatter of results the life of samples exposed to a corrosive environment cannot be correlated with data produced in air. Analysis shows that this is simply untrue and if the two sets of data are plotted a lower and upper trend can be produced, independent of environment and rolling direction, and it is possible to establish a trend of crack growth data within the two bands. This research produced a valid method of calculating the Paris exponent, $\mathrm{m}$. The metallic foam sandwich panel had a Paris exponent, $\mathrm{m}$, of 7.41 .

\subsection{A proposed method of analysis to predict the fatigue life of sandwich panels}

The method of analysis is formed by acquiring the experimental data for aluminium honeycomb and metallic foam sandwich panels. This experimental data is then compared to data produced by calculating the number of cycles to failure. The aim is to calculate the fatigue lives observed experimentally for both aluminium honeycomb and metallic foam sandwich panels. The calculated data will then be used to produce an equation that will predict experimental fatigue life for the complex metallic foam sandwich panels. Conventionally, crack growth rate can be related to the stress intensity factor range using equations (15) and (16).

$$
\begin{gathered}
\Delta K=\mathrm{Y}(\Delta P) \sqrt{\pi a} \\
\frac{d a}{d N} \equiv C(\Delta K)^{m}
\end{gathered}
$$


By rearranging equation (15) and (16) and separating variables and integrating for $\mathrm{m} \neq 2$ gives,

$$
N_{f}=\frac{2}{(m-2) C\left(Y \Delta P \sqrt{\pi)^{m}}\right.}\left(\frac{1}{a i^{(m-2) / 2}}-\frac{1}{a_{f}^{(m-2 / 2}}\right)
$$

Before equation (17) could be solved to calculate residual life from a crack size $\left(a_{i}\right)$ one must know the final or critical crack size $\left(\mathrm{a}_{f}\right)$. For the critical crack condition when $a=\left(a_{f}\right)$ equation (15) can be rewritten as;

$$
a_{f}=\frac{1}{\pi}\left(\frac{K_{c}}{Y P_{\max }}\right)^{2}
$$

Where; $\mathrm{K}_{c}=$ Fracture Toughness

The fracture toughness of aluminium honeycomb sandwich panels is $0.91 \mathrm{MPa} \sqrt{m}$ and 0.85 $\mathrm{MPa} \sqrt{m}$ for Alulight foam. The calculated crack propagation life versus experimental crack propagation life is shown in Figure 24. In Fig. 24 data can be seen for aluminium honeycomb sandwich panels. The graph clearly shows an excellent correlation between calculated and experimental results.

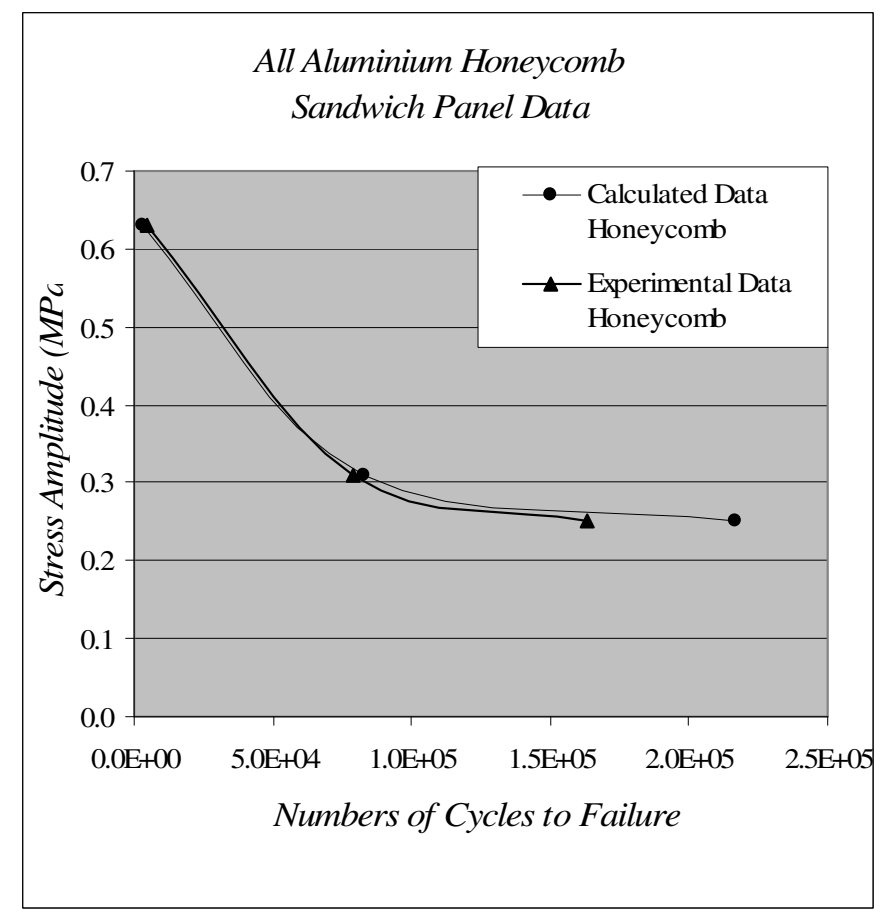

Fig. 24. Calculated Crack Propagation Life versus experimental Crack Propagation Life for Aluminium Honeycomb Sandwich Panel 


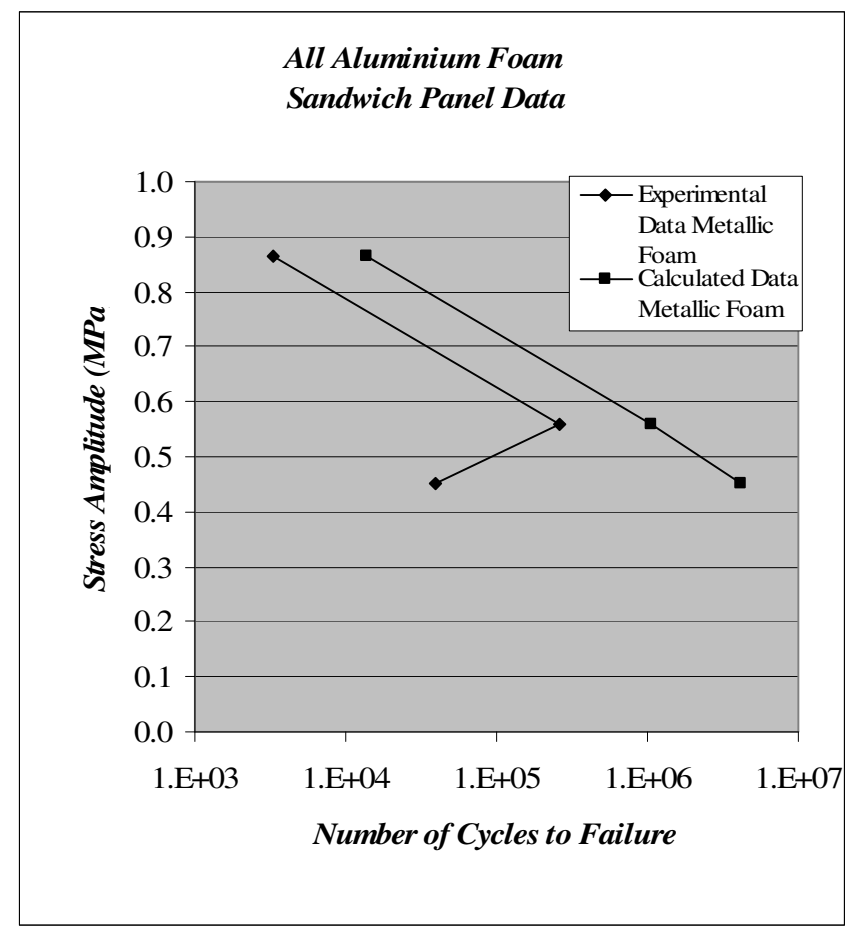

Fig. 25. Calculated Crack Propagation Life versus experimental Crack Propagation Life for Metallic Foam Sandwich Panels

However, the calculated crack propagation life versus experimental crack propagation life for metallic foam sandwich panel is shown in Fig. 25 where it can be clearly seen that calculated data does not correlate with experimental data. The graph illustrates that calculated data always produces a higher number of cycles to failure for metallic foam sandwich panels. The main reason for this is that calculation of stress within the metallic foam structure is complex due to the inhomogenity of the voids within the foam. Equations produced using data from Figs. 24 and 25 were then used to calculate experimental data equation for foam:

Foam Calculated:

$$
\sigma=-0.072 \ln N_{f}+1.5518
$$

Honeycomb calculated:

$$
\sigma=-0.0912 \ln N_{f}+1.3589
$$

Therefore, to plot experimental foam data:

$$
\sigma=\frac{\left(-0.1632 \ln N_{f}-2.9107\right)}{2}
$$




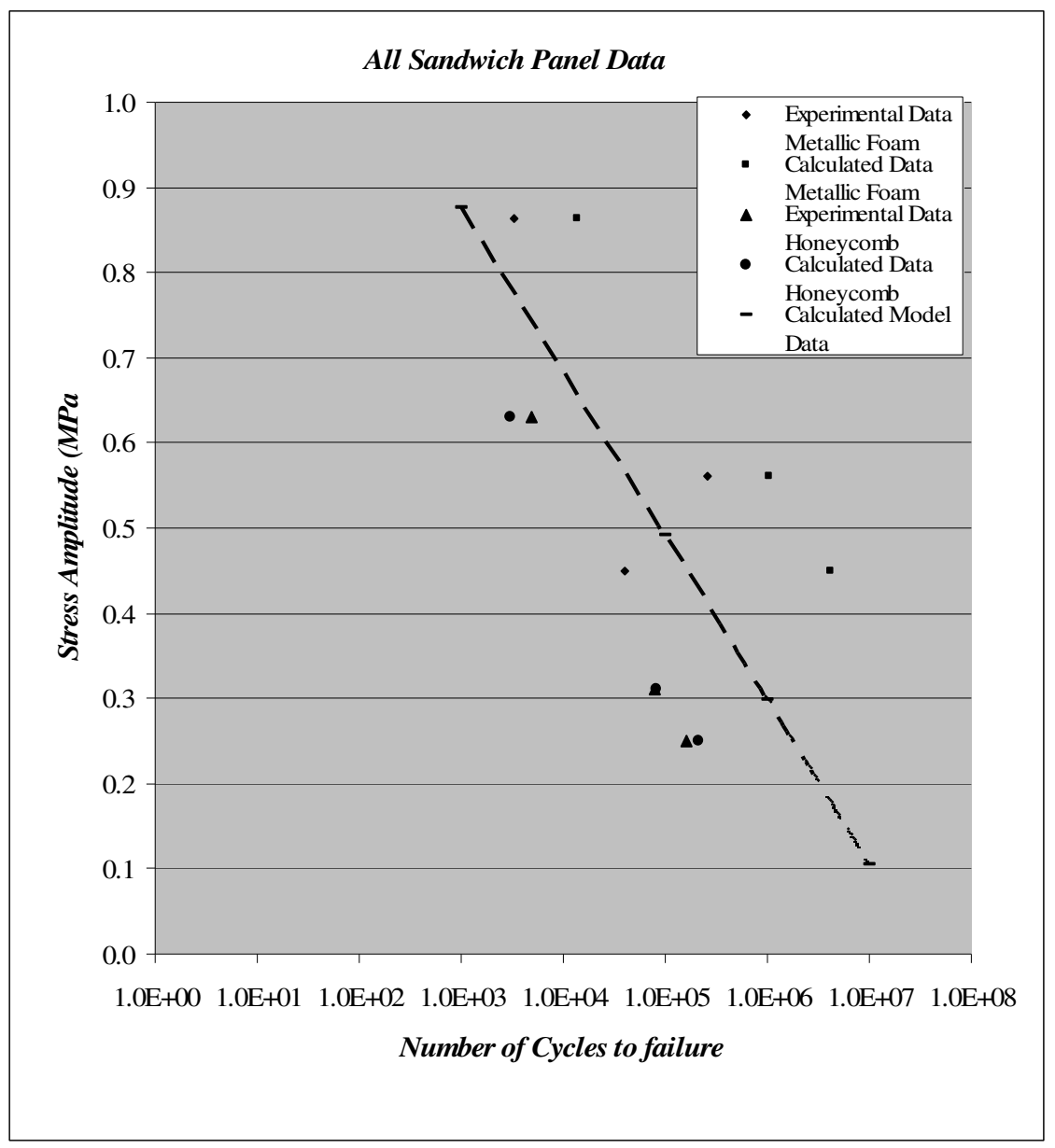

Fig. 26. Calculated Fatigue Life versus Experimental Fatigue Life for Metallic Foam and Aluminium Honeycomb Sandwich Panels

The results of both aluminium honeycomb and metallic foam data for both calculated and experimental cycles to failure is shown in Figure 26. An equation was calculated for each set of data, equations 19 for metallic foam and 20 for aluminium honeycomb respectively. The equations 19 and 20 can then be used to develope an equation 21 to predict the fatigue life of a close cell metallic foam sandwich panel. Using equation 21, calculated life for aluminium honeycomb and metallic foam sandwich panels are compared with original experimental data. What is clear from the Fig. 28 is that all of the experimental data for the two types of specimens correlate with the predicted values. The data correlation proves that a successful model is produced to calculate fatigue life for metallic foam sandwich panels. This model is of extreme importance because it shows that from a structural point of view, metallic foam sandwich panels can successfully replace aluminium honeycomb sandwich panels. 


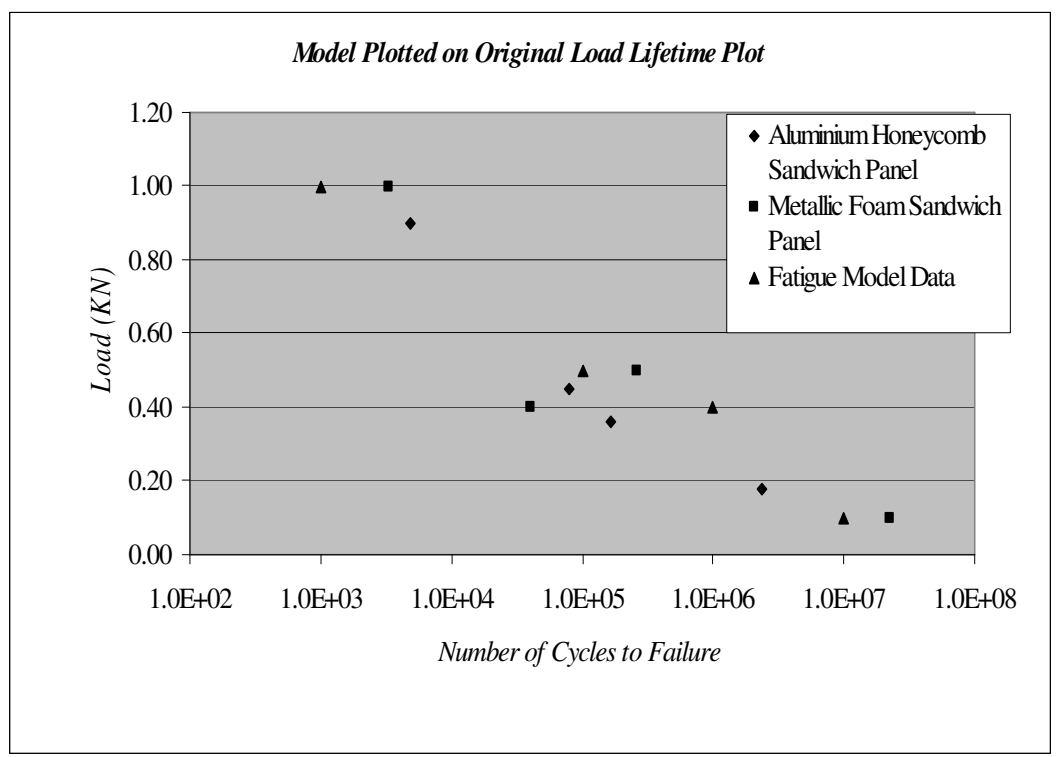

Fig. 27. Showing Fatigue Data for Aluminium Honeycomb, Metallic Foam Sandwich Panel and Calculated Model Data

\section{Concluding remarks}

The influence of processing conditions in the micromechanical behaviour of $\mathrm{Al} / \mathrm{SiC}$ composites has been discussed. Two different manufacturing processes (cast and rolled), three reinforcement percentages $(20 \%, 30 \%, 31 \%)$ and three processing states (as received, HT-1, T6 heat treated) have been compared.

The importance of processing conditions in the micro-structural events of segregation and precipitation has been depicted at the micro/nano level using microhardness measurements and nano-scale phase identification of the matrix-reinforcement interface, and the developments of strengthening mechanisms in the composite have been identified. The HT1 heat treatment condition clearly showed an increase in the microhardness, due to $\beta$ precipitates as well as other phases and oxides formed in the composite. T6 heat treatment showed the highest microhardness values due to formation of $\beta$ precipitates, which contribute to strengthening of the interface.

Microhardness and tensile testing results show that the composite micro-mechanical behaviour is influenced by certain factors. In the absence of precipitates (as received state) or in the case of dispersed precipitates (aluminium matrix) the dominant parameters influencing the micromechanical behaviour of the composite are the reinforcement percentage, the interparticle distance and the mean size of particulates. However, when precipitates are concentrated in the areas close to the interface (T6 condition) these precipitates contribute to the strengthening of the composite material.

The thermographic examination of the materials show that heat treated composite samples exhibit regular crack propagation behaviour. Stress concentration, due to the presence of particle reinforcements, produced controlled crack growth and higher stresses, which were 
related to regular energy release by the material during fracture, indicative of brittle fracture behaviour. On the other hand, the large plastic deformation of the aluminium alloy can be associated with the absence of stress-peaks in conjunction with the monotonic temperature rise for a large part of the temperature / time curve prior to the specimen failure.

A model has been applied to predict the interfacial fracture strength of aluminium in the presence of silicon segregation. This model considers the interfacial energy caused by segregation of impurities at the interface and uses Griffith crack-type arguments to forecast the energy change in terms of the coincidence site stress describing the interface and the formation energies of impurities at the interface. Based on Griffith's approach, the fracture toughness of the interface was expressed in terms of interfacial critical strain energy release rate and elastic modulus. The interface fracture toughness was determined as a function of the macroscopic fracture toughness and mechanical properties of the composite using two different approaches, a toughening mechanism model based on crack deflection and interface cracking and a stress transfer model. The model shows success in making prediction possible of trends in relation to segregation and interfacial fracture strength behaviour in SiC particle-reinforced aluminium matrix composites. The model developed here can be used to predict possible trends in relation to segregation and the interfacial fracture strength behaviour in metal matrix composites. The results obtained conclude that the role of precipitation and segregation on the mechanical properties of $\mathrm{Al} / \mathrm{SiCp}$ composites is crucial, affecting overall mechanical behaviour.

The tension-tension fatigue properties of $\mathrm{Al} / \mathrm{SiC}$ composites as a function of heat treatment have been discussed as well as the associated damage development mechanisms. The composites exhibited endurance limits ranging from $70 \%$ to $85 \%$ of their UTS. The T6 composites performed significantly better in absolute values but their fatigue limit fell to the $70 \%$ of their ultimate tensile strength. This behaviour is linked to the microstructure and the good matrix-particulate interfacial properties. In the case of the HT1 condition, the weak interfacial strength led to particle/matrix debonding. In the T1 condition the fatigue behaviour is similar to the HT1 condition although the quasi static tensile tests revealed a less ductile nature.

The crack growth behaviour of particulate-reinforced metal matrix composites was also investigated. Aluminium A359 reinforced with 31\% of $\mathrm{SiC}$ particles subjected to two different thermal treatments, as well as wrought aluminium $2 \times x x$ series specimens, have been examined using thermographic mapping. Heat treated composites, and especially those samples subjected to T6 aged condition, exhibited different behaviour of crack propagation rate and stress intensity factor range than the as-received composite specimens. Furthermore, the composite specimens exhibited different fatigue crack growth rate characteristics than the base aluminium alloy samples. It becomes evident that the path of fatigue crack growth depends on the heat treatment conditions, where crack propagation relies on strengthening mechanisms, such as precipitation hardening. The microstructure of the interphase region was also found to play a significant role in the crack growth behaviour of particulate-reinforced composites. In this sense, $\mathrm{T} 6$ heat treated $\mathrm{Al} / \mathrm{SiCp}$ composite samples exhibits better interphase bonding behaviour than the other composite systems.

The fatigue crack growth curves reveal an approximately linear, or Paris law region, fitting the function $\mathrm{da} / \mathrm{dN}=\mathrm{C} \Delta \mathrm{K}$. Crack growth rate vs. stress intensity range curves have been obtained using lock-in thermography. These results are in agreement with crack growth rate measurements using the conventional compliance method and calculations based on the 
Paris law. It becomes, therefore, evident that lock-in thermography has a great potential for evaluating nondestructively the fracture behaviour of metallic composite materials.

Finally, cyclic deformation data reveals that metallic foam sandwich panel samples do not produce consistent results with acceptable repeatability of results but by using calculated crack propagation life data and experimental data for both aluminium honeycomb and metallic foam sandwich panels a method of analysis has been proposed to predict fatigue life of metallic foam sandwich panels.

\section{References}

[1] K.G. Kreider, Composite Materials, in: Metallic Matrix Composites, Volume 4, Academic Press, New York and London (1974).

[2] D.J. Lloyd, Particle Reinforced Aluminium and Magnesium Matrix Composites, Int. Mater. Rev. 39, 1-23 (1994).

[3] N.F. Mott and F.R.N. Nabarro, An attempt to estimate the degree of precipitation hardening, with a simple model, Proc Phys Soc 52, 85 (1940).

[4] H.B. Aaron and H.I. Aaronson, Growth of grain boundary precipitates in $\mathrm{Al}-4 \% \mathrm{Cu}$ by interfacial diffusion, Acta Meter. 16, 789 (1968).

[5] H.B. Aaron, D. Fainstein and G.R. Kotler, Diffusion-Limited Phase Transformations: A Comparison and Critical Evaluation of the Mathematical Approximations, J. Appl. Phys. 41(11), 4404-4410 (1970).

[6] H.R. Shercliff and M.F. Ashby, A process model for age hardening of aluminium alloys I. The model, Acta Mater. 38, 1789-1802 (1990).

[7] R.A. Carolan and R.G. Faulkner, Grain boundary precipitation of M23C6 in an austenitic steel, Acta Mater. 36, 257-266 (1988).

[8] S.T. Hasan, J.H. Beynon and R.G. Faulkner, Role of segregation and precipitates on interfacial strengthening mechanisms in $\mathrm{SiC}$ reinforced aluminium alloy when subjected to thermomechanical processing, J. Mater. Process. Technol. 153-154, 757763 (2004).

[9] M. Manoharan and J.J. Lewandowski, In-situ Deformation Studies of an Aluminum Metal-Matrix Composite in a Scanning Electron Microscope, Scr. Metall. 23, 18011804 (1989).

[10] M. Manoharan and J.J. Lewandowski, Effect of Reinforcement Size and Matrix Microstructure on the Fracture Properties of an Aluminum Metal-Matrix Composite, Mater. Sci. Eng. A 150, 179-186 (1992).

[11] S.T. Hasan, Effect of heat treatment on interfacial strengthening mechanisms of second phase particulate reinforced aluminium alloy, 14th International Metallurgical and Materials Conference (Metal 2005), Hradec nad Moravici, Czech Republic, (2005).

[12] J.J. Lewandowski, C. Liu and W.H. Hunt Jr., Effects of Microstructure and Particle Clustering on Fracture of an Aluminum Metal Matrix Composite, Mater. Sci. Eng. A 107, 241-255 (1989).

[13] G. Rozak, J.J. Lewandowski, J.F. Wallace and A. Altmisoglu, Effects of Casting Conditions and Deformation Processing on A356 Aluminum and A356-20\% SiC Composites, J. Compos. Mater. 26(14), 2076-2106 (1992).

[14] Bitzer T.1997 Honeycomb Technology: materials, design, manufacturing, applications and testing. Chapman \& Hall.

[15] Alulight International $\mathrm{GmbH}$ 
[16] Burman, M and Zenkert D, 1997, Fatigue in Foam Core Sandwich Beams International Journal of Fatigue, Vol 19, Issue 7, pp $551-561$

[17] Shipsha, A, Burman, M and Zenkert, D. 1999, On Mode I Fatigue Crack Growth in Foam Core Materials for Sandwich Panels. Journal of Sandwich Structures and Materials Vol 2, Issuse 2, pp 103-116

[18] Banhart, J and Brinkers, W, 1999, Fatigue Behaviour of Aluminium Foams, Journal of Materials Science Letters, 18:pp 617-619

[19] Olurin, OB, McCullough, Fleck NA and Ashby MF, 2001, Fatigue crack Propagation in Aluminium Alloy Foams International Journal of Fatigue, Vol 23, Issue 5, pp 375-382

[20] Myriounis D. P., S. T. Hasan, N. M. Barkoula, A. Paipetis, T. E. Matikas, "Effects of heat treatment on microstructure and the fracture toughness of $\mathrm{SiCp} / \mathrm{Al}$ alloy metal matrix composites", Journal of Advanced Materials, vol. 41(3), pp. 18-27 (2009).

[21] Myriounis D. P., S. T. Hasan and T. E. Matikas, "Influence of Processing Conditions on the Micro-Mechanical Properties of Particulate-Reinforced Aluminium Matrix Composites", Advanced Composites Letters, vol. 17(3), pp. 75-85 (2008).

[22] Myriounis D. P., S. T. Hasan and T. E. Matikas, "Microdeformation behaviour of Al-SiC Metal Matrix Composites", Composite Interfaces, vol. 15(5), pp. 485-514 (2008).

[23] Myriounis D. P., S. T. Hasan and T. E. Matikas, "Heat Treatment and Interface Effects on the Mechanical Behaviour of SiC-Particle Reinforced Aluminium Matrix Composites", Journal of ASTM International - JAI, vol. 5(7), published on-line, DOI: 10.1520/JAI101624 (2008).

[24] D. G. Aggelis, E. Z. Kordatos, T. E. Matikas, "Acoustic Emission for Fatigue Damage Characterization in Metal Plates", Mechanics Research Communications", Mechanics Research Communications, vol. 38, pp. 106-110 (2011).

[25] E. Z. Kordatos, D. P. Myriounis, S. T. Hasan, T. E. Matikas, "Monitoring the fracture behavior of $\mathrm{SiCp} / \mathrm{Al}$ alloy composites using infrared lock-in thermography", Proceedings of SPIE - The International Society for Optical Engineering, Vol. 7294, Article number 72940X, 2009.

[26] Myriounis D. P., E.Z. Kordatos, S. T. Hasan, T. E. Matikas, “Crack-tip stress field and fatigue crack growth monitoring using infrared lock-in thermography in $\mathrm{SiCp} / \mathrm{Al}$ alloy composites", Strain, published on-line, DOI: 10.1111/j.1475-1305.2009.00665.x (2010).

[27] C. J. McMahon Jr., V. Vitek, Effects of segregated impurities on intergranular Fracture Energy, Acta Metall, 27(4), 507-513 (1979).

[28] L. Shoyxin, S. Lizhi, L. Huan, L. Jiabao, W. Zhongguang, Stress carrying capability and interface fracture toughness in $\mathrm{SiC} / 6061 \mathrm{Al}$ model materials, Journal of materials science letters 16, 863-869 (1997).

[29] X. Q. Xu, D. F. Watt, Basic role of a hard particle in a metal matrix subjected to tensile loading, Acta Metal. Mater., 42(11), 3717-3729 (1994).

[30] H. L. Cox, The elasticity and strength of paper and other fibrous materials, Br. J. Appl. Phys.,3, $72-79$ (1952).

[31] J. Llorca, An analysis of the influence of reinforcement fracture on the strength of discontinuously- reinforced metal matrix composites, Acta Metall. Mater., 43(1), 181-192 (1995).

[32] Myriounis D. P., S. T. Hasan, T. E. Matikas, "Predicting interfacial strengthening behaviour of particulate reinforced MMC - A micro-mechanistic approach", Composite Interfaces, vol. 17(4), pp. 347-355 (2010). 
[33] Z. Wang, R. J. Zhang, Microscopic characteristics of fatigue crack propagation in aluminium alloy based particulate reinforced metal matrix composites, Acta metal. mater., 42(4), 1433-1445 (1994).

[34] R. G. Faulkner, Impurity diffusion constants and vacancy binding energies in solids, Mater. Sci. Technol., 1(6), 442-447 (1985).

[35] Hasan ST, Beynon JH, Faulkner RG., Role of segregation and precipitates on interfacial strengthening mechanisms in $\mathrm{SiC}$ reinforced aluminium alloy when subjected to thermomechanical processing, Journal of Materials Processing Technology 153154:758-764 (2004).

[36] R. G. Faulkner, L. S. Shvindlerman, Grain Boundary Thermodynamics, Structures and Mechanical Properties, Materials Science Forum, 207-209, 157-160 (1996). 


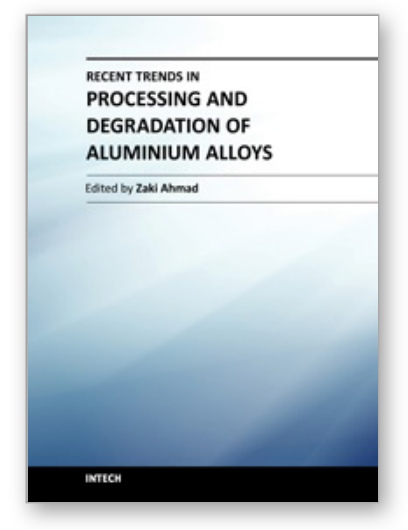

\section{Recent Trends in Processing and Degradation of Aluminium Alloys \\ Edited by Prof. Zaki Ahmad}

ISBN 978-953-307-734-5

Hard cover, 516 pages

Publisher InTech

Published online 21, November, 2011

Published in print edition November, 2011

In the recent decade a quantum leap has been made in production of aluminum alloys and new techniques of casting, forming, welding and surface modification have been evolved to improve the structural integrity of aluminum alloys. This book covers the essential need for the industrial and academic communities for update information. It would also be useful for entrepreneurs technocrats and all those interested in the production and the application of aluminum alloys and strategic structures. It would also help the instructors at senior and graduate level to support their text.

\section{How to reference}

In order to correctly reference this scholarly work, feel free to copy and paste the following:

Theodore E. Matikas and Syed T. Hasan (2011). Deformation Characteristics of Aluminium Composites for Structural Applications, Recent Trends in Processing and Degradation of Aluminium Alloys, Prof. Zaki Ahmad (Ed.), ISBN: 978-953-307-734-5, InTech, Available from: http://www.intechopen.com/books/recent-trends-inprocessing-and-degradation-of-aluminium-alloys/deformation-characteristics-of-aluminium-composites-forstructural-applications

\section{INTECH}

open science | open minds

\section{InTech Europe}

University Campus STeP Ri Slavka Krautzeka 83/A 51000 Rijeka, Croatia Phone: +385 (51) 770447

Fax: +385 (51) 686166 www.intechopen.com

\section{InTech China}

Unit 405, Office Block, Hotel Equatorial Shanghai No.65, Yan An Road (West), Shanghai, 200040, China 中国上海市延安西路65号上海国际贵都大饭店办公楼405单元 Phone: +86-21-62489820

Fax: $+86-21-62489821$ 
(C) 2011 The Author(s). Licensee IntechOpen. This is an open access article distributed under the terms of the Creative Commons Attribution 3.0 License, which permits unrestricted use, distribution, and reproduction in any medium, provided the original work is properly cited. 